\title{
Protein disulfide isomerase A1-associated pathways in the development of stratified breast cancer therapies
}

\author{
EMYR YOSEF BAKKER ${ }^{1}$, MASAYUKI FUJII ${ }^{2}$, MARIJA KRSTIC-DEMONACOS ${ }^{3}$, \\ CONSTANTINOS DEMONACOS ${ }^{4}$ and RASHED ALHAMMAD ${ }^{4,5}$
}

\author{
${ }^{1}$ School of Medicine, University of Central Lancashire, Preston, Lancashire PR1 2HE, UK; ${ }^{2}$ Department of \\ Biological and Environmental Chemistry, Faculty of Humanity Oriented Science and Engineering, Kindai University, \\ Iizuka, Fukuoka 820-8555, Japan; ${ }^{3}$ University of Salford, School of Science, Engineering and Environment, \\ Salford M5 4WT; ${ }^{4}$ Faculty of Biology Medicine and Health, School of Health Science, Division of Pharmacy and \\ Optometry, University of Manchester, Manchester M13 9PT, UK; ${ }^{5}$ Department of Pharmacology and Toxicology, \\ Faculty of Medicine, Health Sciences Centre, Kuwait University, Sulaibekhat 90805, Kuwait
}

Received July 29, 2021; Accepted December 7, 2021

DOI: 10.3892/ijo.2022.5306

\begin{abstract}
The oxidoreductase protein disulfide isomerase A1 (PDIA1) functions as a cofactor for many transcription factors including estrogen receptor $\alpha(\mathrm{ER} \alpha)$, nuclear factor $(\mathrm{NF})-\kappa \mathrm{B}$, nuclear factor erythroid 2-like 2 (NRF2) and regulates the protein stability of the tumor suppressor p53. Taking this into account we hypothesized that PDIA1, by differentially modulating the gene expression of a diverse subset of genes in the ER $\alpha$-positive vs. the ER $\alpha$-negative breast cancer cells, might modify dissimilar pathways in the two types of breast cancer. This hypothesis was investigated using RNA-seq data from PDIA1-silenced MCF-7 (ER $\alpha$-positive) and MDA-MB-231 (ER $\alpha$-negative) breast cancer cells treated with either interferon $\gamma($ IFN- $\gamma)$ or etoposide (ETO), and the obtained data were further analyzed using a variety of bioinformatic tools alongside clinical relevance assessment via Kaplan-Meier patient survival curves. The results highlighted the dual role of PDIA1 in suppressing carcinogenesis in the ER $\alpha(+)$ breast cancer patients by negatively regulating the response to reactive oxygen species (ROS) and promoting carcinogenesis by inducing cell cycle progression. In the $\operatorname{ER} \alpha(-)$ breast cancer patients, PDIA1 prevented tumor development by modulating
\end{abstract}

Correspondence to: Dr Constantinos Demonacos, Faculty of Biology Medicine and Health, School of Health Science, Division of Pharmacy and Optometry, University of Manchester, Oxford Road, Manchester M13 9PT, UK

E-mail: constantinos.demonacos@manchester.ac.uk

Dr Rashed Alhammad, Department of Pharmacology and Toxicology, Faculty of Medicine, Health Sciences Centre, Kuwait University, Sulaibekhat 90805, Kuwait

E-mail: rashed.alhammad@ku.edu.kw

Key words: breast cancer, protein disulfide isomerase, transcription, oxidative stress, personalized medicine
$\mathrm{NF}-\kappa \mathrm{B}$ and p53 activity and cell migration and induced breast cancer progression through control of cytokine signaling and the immune response. The findings reported in this study shed light on the differential pathways regulating carcinogenesis in $\operatorname{ER} \alpha(+)$ and $\operatorname{ER} \alpha(-)$ breast cancer patients and could help identify therapeutic targets selectively effective in $\operatorname{ER} \alpha(+)$ vs. $\operatorname{ER} \alpha(-)$ patients.

\section{Introduction}

Protein disulfide isomerases (PDIs) are involved in a wide range of biological pathways as mediators of oxidative folding in the endoplasmic reticulum $(1,2)$, in the formation, breakage, and rearrangement of disulfide bonds $(1,3)$, and in the regulation of apoptosis, exerting both pro-apoptotic and pro-survival effects $(4,5)$. The PDI family member prolyl 4-hydroxylase $\beta$ (P4HB, also known as PDIA1) functions as a chaperone that assists protein folding by inhibiting the aggregation of partially folded or damaged polypeptides (6). Recent findings have implicated PDIA1 in the processes of antigen processing and presentation, immunomodulation and tumor immunorecognition (4,7-9).

PDIA1 has been shown to play an important role in various stages of carcinogenesis in a wide variety of cancers, being involved in the early stages of carcinogenesis possibly by contributing to the management of misfolded and non-functional proteins (5) as well as in the evasion of the immunosurveillance (4). Evidence has been presented that PDI family members are involved in the proliferation and metastasis of brain, kidney, and lung cancers $(10,11)$. Overexpression of PDI family members has been positively correlated with metastasis and invasion of breast cancer (12). For instance, significantly higher PDIA1 levels have been observed in axillary lymph node metastatic breast tumor compared to primary breast tumors (13). In addition, PDIA1 mRNA levels have been found to be positively correlated with malignant glioma metastasis and invasion (14) and the epithelial-mesenchymal transition (EMT) of liver cancer cells (15-17). The potential 
molecular mechanisms by which PDIA1 contributes to metastasis include the regulation of the hypoxia-inducible factor-1 $\alpha$ (HIF-1 $\alpha)$ pathway $(17,18)$, and induction of matrix metalloproteinase-9 (MMP-9) secretion (19) or other metalloproteases such as the disintegrin and metalloprotease domain family member ADAM metallopeptidase domain 17 (ADAM17) (20).

PDIA1 is mainly localized in the endoplasmic reticulum, but cell surface and nuclear localization under certain micro-environmental conditions have also been reported (21,22). Distinct PDIA1 subcellular locations determine diverse PDIA1 signaling networks including the regulation of the cellular redox state which in turn regulates its function (2). Nuclear PDIA1 has been shown to play a role in the regulation of the transcriptional activity of redox responsive transcription factors $(23,24)$. Indeed, PDIA1 has been shown to directly interact and function as an estrogen receptor (ER) $\alpha$ transcriptional cofactor $(25,26)$. In addition, PDIA1 suppresses nuclear factor $(\mathrm{NF})-\kappa \mathrm{B}$ transcriptional activity $(27,28)$ and regulates p53 protein stability $(29,30)$. These observations raise the possibility that PDIA1 regulates the crosstalk between ER $\alpha$ and NF- $\mathrm{NB}$ (31). Other redox-responsive transcription factors associated with PDIA1 include HIF-1 $\alpha$ (18) and nuclear factor (erythroid-derived 2)-like 2 (NRF2) (32). PDIA1 is also implicated in regulating the transcription of the gene targets of thyroid hormone receptors $\alpha$ and $\beta(33,34)$.

Several endoplasmic reticulum chaperones including PDI have been detected in the mitochondria (35) and the mitochondrial and the endoplasmic reticulum contact sites (MERC) (36). The function of the mitochondrial PDIs has not been elucidated clearly but there is evidence to suggest that PDIs regulate the exchange of $\mathrm{Ca}^{2+}$ between the endoplasmic reticulum and mitochondria, mitochondrial energy generation (37) and the immune response to tumor cells (38), suggesting that PDIs might affect carcinogenesis via multiple pathways. Given that PDIA1 protein levels are breast cancer subtype-specific $(4,13)$ and taking into account the fact that PDIA1 functions as a co-modulator for several transcription factors including ER $\alpha$ (26), it was hypothesized that PDIA1 would differentially affect carcinogenesis in ER $\alpha$-positive vs. $\mathrm{ER} \alpha$-negative breast cancer cells.

In the present study, PDIAI gene expression was silenced in the ER $\alpha$-positive MCF-7 and the ER $\alpha$-negative MDA-MB-231 breast cancer cells and the expression of genes under conditions stimulating reactive oxygen species (ROS) generation (treatment with interferon- $\gamma(\mathrm{IFN}-\gamma)$ (39) or etoposide (ETO) (40) was followed using RNA-seq. Kaplan-Meier survival curves of the modulated genes detected by RNA-seq were generated to identify whether high or low expression of the upregulated or downregulated genes in the ER $\alpha$-positive (MCF-7) or triple-negative breast cancer (TNBC) cells (MDA-MB-231) had positive or negative effect on the overall survival (OS) of the ER $\alpha$-positive or ER $\alpha$-negative breast cancer patients, respectively. The results indicated that PDIA1, in the ER $\alpha$-positive breast cancer patients, suppresses carcinogenesis by negatively regulating catabolic processes of ROS. PDIA1 was found to induce carcinogenesis by affecting cell cycle progression at the $\mathrm{G} 2 / \mathrm{M}$ checkpoint alongside spindle formation in the ER $\alpha$-positive breast cancer patients. In the $\mathrm{ER} \alpha$-negative breast cancer patients, PDIA1 was found to prevent tumor development by regulating the response to $\mathrm{NF}-\kappa \mathrm{B}$ signaling, mitochondrial biogenesis, glycolysis and the process of metastasis. PDIA1 induced breast cancer progression in ER $\alpha$-negative breast cancer patients by modifying the immune response, cytokine signaling and calcium homeostasis. The findings reported here shed new light on the differential pathways inducing carcinogenesis in the ER $\alpha$-positive and $E R \alpha$-negative breast cancer patients and could assist in the identification of selectively beneficial therapeutic targets for ER $\alpha$-positive or ER $\alpha$-negative patients.

\section{Materials and methods}

Cell culture. The human breast carcinoma cell lines MCF-7 (expressing ER $\alpha$ and wild-type p53) and MDA-MB-231 [ER $\alpha$-negative, bearing mutated p53 (R280K)] were obtained from the European Collection of Cell Cultures (ECACC) and maintained in Dulbecco's modified Eagle's medium (DMEM) (Sigma-Aldrich; Merck KGaA) supplemented with $10 \%$ fetal bovine serum (FBS; Gibco; Thermo Fisher Scientific, Inc.) and $1 \%$ penicillin/streptomycin (Lonza Group, Ltd.) at $37^{\circ} \mathrm{C}$ in a humidified atmosphere containing $5 \% \mathrm{CO}_{2}$ until they reached $70 \%$ confluency. Where indicated, cells were treated with $10 \mathrm{ng} / \mathrm{ml}$ IFN- $\gamma$ (Sigma-Aldrich; Merck KGaA) for $24 \mathrm{~h}$ or $10 \mu \mathrm{M}$ etoposide (ETO) for $24 \mathrm{~h}$ (Sigma-Aldrich; Merck $\mathrm{KGaA})$.

siRNA transfection. Concentration of $5 \mu \mathrm{M}$ of the siGENOME PDIA1 siRNA and $5 \mu \mathrm{M}$ of the siGENOME non-targeting siRNA pool was added to each well containing $2 \times 10^{5}$ cells in DMEM and incubated for $72 \mathrm{~h}$ according to the suppliers' instructions (Dharmacon, UK) as described previously (4). The sequences of the siRNAs used are indicated as follows: siGENOME PDIA1-targeting siRNA pool: ACAGGACGGUCA UUGAUUA, GGACGGUCAUUGAUUACAA, CCAAGAG UGUGUCUGACUA, and CAGAGAGGAUCACAGAGUU; siGENOME non-targeting (scramble) siRNA pool: UAGCGA CUAAACACAUCAA, UAAGGCUAUGAAGAGAUAC, AUGUAUUGGCCUGUAUUAG, and AUGAACGUGAAU UGCUCAA.

Western blotting. Cellular extracts from MCF-7 and MDA-MB-231 and $30 \mu \mathrm{g}$ of total protein per sample were loaded on a $20 \%$ precast polyacrylamide gel and transferred to a PVDF membrane. The membranes were then incubated in 5\% milk in PBS-0.1\% Tween-20 (v/v) with anti-P4HB antibody (Santa Cruz Biotechnology, sc-74551) (dilution 1:500) or $\beta$-actin (Sigma-Aldrich; Merck KGaA; A1978) (dilution $1: 10,000)$ overnight at $4^{\circ} \mathrm{C}$. After incubation with secondary anti-mouse immunoglobulin $\mathrm{G}$ conjugated to horseradish peroxidase (GE Healthcare) (dilution 1:1,000) in $2.5 \%$ milk in PBS- $0.1 \%$ Tween-20 (v/v) for $1 \mathrm{~h}$ at $25^{\circ} \mathrm{C}$, the protein bands were visualized using the ChemiDoc MP imaging system (Bio-Rad Laboratories) The blots were quantified using ImageJ version 1.51 (National Institutes of Health).

RNA extraction. MCF-7 and MDA-MB-231 breast cancer cell lines were seeded in 6 -well plates at a concentration of $3 \times 10^{5}$ cells per well for $24 \mathrm{~h}$ after treatment. RNA was extracted according to the RNeasy Mini Kit supplier instructions 
(Qiagen, UK). After collecting RNA, the samples were maintained at $-80^{\circ} \mathrm{C}$ before sequencing carried out by the Next Generation Sequencing Facility (University of Leeds, UK).

RNA sequencing. Initial alignment of RNA transcript counts, sequence short reads, and normalization were carried out by the Next Generation Sequencing Facility (University of Leeds, UK). Sequence data in Fastq format were quality-checked using FastQC software (http://www.bioinformatics.babraham. ac.uk/projects/fastqc/). Cutadapt version 1.16 software (https:/cutadapt.readthedocs.org/en/stable/) was used to trim poor quality bases (Phred quality score <20) and contaminating adapter sequences from raw reads. Reads trimmed to fewer than 30 were discarded. Reads were aligned to a human (hg38) genome reference sequences, obtained from the UCSC database (41) using the splicing-aware STAR aligner (42). STAR aligner was run with known splice junctions supplied in GTF file format, obtained from the UCSC database using Table Browser tool $(43,44)$. The resulting alignments in BAM file format were checked for quality using QualiMap software (44) and Picard tools version 1.90 (http://picard.sourceforge.net). Picard tools also used to mark PCR/Optical duplicate alignments. BAM files were indexed using Samtools software (45) and visualised using IGV browser (46) to check for genomic DNA contamination and the presence of PCR duplicates. Bioconductor R package RSubread (47) was used to extract raw sequenced fragment counts per transcript using the RefSeq hg38 annotation dataset used by STAR during alignment. Multi-mapping read pairs were counted as a fraction of all equivalent alignments. Read count data were generated with the inclusion of reads marked as PCR/optical duplicates.

Filtration of the gene list. Significantly downregulated or upregulated genes (Benjamini-Hochberg <0.01) in the PDIA1-silenced MCF-7 and MDA-MB-231 treated with IFN- $\gamma$ or ETO compared to MCF-7 and MDA-MB-231 cells expressing PDIAl treated with IFN- $\gamma$ (39) or ETO (40) were selected. To visualize the overall changes in gene expression between PDIA1-silenced and scramble-transfected MCF-7 and MDA-MB-231 cells, the log value of the change in gene expression was graphed against the normalized read count for each transcript using the plotMA function of the DeSeq2 R package (47). The read count data required for each pairwise analysis was imported into the $\mathrm{R}$ package DeSeq 2 and the effect size of each sample's library was defined and used to normalize the read count data.

Kaplan-Meier overall survival analysis. To understand the clinical importance of the genes identified and filtered from the RNA-seq data, the Kaplan-Meier Plotter website (http://kmplot. com/analysis/) was utilized. For this purpose, Kaplan-Meier (KM) plots for ER $\alpha$-positive and ER $\alpha$-negative patients were generated for the genes identified to be upregulated or downregulated in the RNA-seq data (48). The following parameters were selected: Survival: OS, Split patients by: upper quartile, Follow-up threshold: 240 months, Probe set option: only JetSet best probe sets (49), ER status-IHC: ER-positive (for the genes upregulated or down regulated in MCF-7 cells) or ER negative (for the genes upregulated or downregulated in MDA-MB-231 cells) ER status-array: ER positive (for the genes upregulated or downregulated in MCF-7 cells) and ER negative (for the genes upregulated or down regulated in MDA-MB-231 cells). Log rank P-values $<0.05$ for the KM plots of all genes was considered statistically significant.

cBioPortal analysis. The Pearson correlation coefficient for the comparison of PDIA1 mRNA levels with those of the genes upregulated or downregulated in the PDIAl-silenced MCF-7 cells treated with etoposide (ETO) or interferon $\gamma(\mathrm{IFN}-\gamma)$ in breast cancer patients was explored using the cBioPortal platform (http://cbioportal.org) in combination with data provided in the Breast Cancer (SMC 2018) database using the mRNA expression z-scores relative to all sample (RNA seq TPM-168 samples) options.

Functional annotation. In order to understand the biological importance of the gene lists generated from the previous section, the GeneCards tool (50) was used to identify linked genes to the genes listed in Tables I and II. After this, Metascape tool (51) was employed. Gene lists were entered in the metascape tool using the Official Gene Symbol as the identifier and Homo sapiens as the species.

Identification of repurposed drugs. Following the identification of genes important for breast cancer patient survival, the potential clinical targeting of each gene was explored via DRUGSURV (52). Genes exerting oncogenic function that were identified as statistically significant for patient OS via KM Plotter were queried in turn, and the approved drugs that targeted the genes directly or indirectly were recorded.

\section{Results}

Since PDIA1 regulates the transcriptional activity of ER $\alpha$, RNA-seq was employed to investigate whether this oxidoreductase differentially affected gene expression in the ER $\alpha$-positive (MCF-7) vs. the ER $\alpha$-negative (MDA-MB-231) breast cancer cells. The differences in the gene expression of genes involved in the oxidative stress pathways were explored in cells treated with either IFN- $\gamma$ or ETO, both of which are known to induce ROS generation $(39,40)$.

Genes upregulated and downregulated in MCF-7 and MDA-MB-231 breast cancer cells in the absence of PDIAI under oxidative stress conditions. Total mRNA obtained from MCF-7 (Fig. 1A and B) or MDA-MB-231 (Fig. 1C and D) cells transfected with either scramble or specific siRNA to silence PDIAl gene expression and treated with either ETO (Fig. 1A and C) or IFN- $\gamma$ (Fig. 1B and D) was submitted to RNA-seq analysis. The transfection efficiency for the PDIA1-siRNA transfected MCF-7 cells compared to the transfection efficiency for the scramble siRNA was $67.13 \%$ (Fig. 1E). The transfection efficiency for the PDIA1-siRNA transfected MDA-MB-231 cells compared to the transfection efficiency for the scramble siRNA was $96.67 \%$ (Fig. 1F).

The total number of genes exhibiting statistically significant downregulation in ETO-treated MCF-7 cells in which PDIAl gene expression had been silenced compared with ETO-treated MCF-7 cells transfected with scramble siRNA was 841 , and the total number of genes upregulated under 
Table I. Genes upregulated or downregulated in interferon $\gamma$ (IFN- $\gamma$ ) or etoposide (ETO)-treated MCF-7 cells in which PDIAl gene expression was silenced compared to PDIA1-expressing IFN- $\gamma$ - or ETO-treated MCF-7 cells.

\begin{tabular}{|c|c|}
\hline \multicolumn{2}{|c|}{ MCF-7 cells } \\
\hline Upregulated & Downregulated \\
\hline LICAM & $A U R K A$ \\
\hline$M A G E D 1$ & $B U B 1$ \\
\hline$M D K$ & $C C N B 2$ \\
\hline PHLDA2 & $C D C 25 A$ \\
\hline$P R D X 2$ & $C D C 25 C$ \\
\hline PTPRS & $C E N P F$ \\
\hline PYCRI & CKAP5 \\
\hline RHOD & $E 2 F 8$ \\
\hline SMAD6 & ESPL1 \\
\hline$T K T$ & FEN1 \\
\hline$U C P 2$ & GTSE1 \\
\hline & $J U N D$ \\
\hline & KIF 11 \\
\hline & KIF $20 A$ \\
\hline & $N E K 2$ \\
\hline & NUSAP1 \\
\hline & PKMYT1 \\
\hline & $R A C G A P I$ \\
\hline & $R A N B P 1$ \\
\hline & S100PBP \\
\hline & TACC 3 \\
\hline & TRIP13 \\
\hline & $T U B B$ \\
\hline & $U B E 2 C$ \\
\hline
\end{tabular}

$P D I A 1$, protein disulfide isomerase A1; AURKA, aurora kinase A; $B U B 1, \mathrm{BUB} 1$ mitotic checkpoint serine/threonine kinase; $C C N B 2$, cyclin $\mathrm{B} 2$; $C D C 25 A$, cell division cycle $25 \mathrm{~A} ; C D C 25 C$, cell division cycle $25 \mathrm{C}$; $C E N P F$, centromere protein $\mathrm{F}$; $C K A P 5$, cytoskeleton associated protein $5 ; E 2 F 8$, E2F transcription factor 8; ESPL1, extra spindle pole bodies like 1, separase; FEN1, flap structure-specific endonuclease 1; GTSE1, G2 and S-phase expressed 1; JUND, JunD proto-oncogene; KIF 11, kinesin family member 11; KIF20A, kinesin family member 20A; L1CAM, L1 cell adhesion molecule; MAGED1, MAGE family member D1; $M D K$, midkine; NEK2, NIMA related kinase 2; NUSAP1, nucleolar and spindle associated protein 1 ; PHLDA2, pleckstrin homology like domain family A member 2; $P K M Y T 1$, protein kinase, membrane associated tyrosine/threonine 1; $P R D X 2$, peroxiredoxin 2; PTPRS, protein tyrosine phosphatase receptor type $\mathrm{S} ; P Y C R 1$, pyrroline-5-carboxylate reductase 1; $R A C G A P 1$, Rac GTPase activating protein 1; RANBP1, RAN binding protein $1 ; R H O D$, ras homolog family member D; S10OPBP, S100P binding protein; SMAD6, SMAD family member 6; TACC3, transforming acidic coiled-coil containing protein $3 ; T K T$, transketolase; TRIP13, thyroid hormone receptor interactor $13 ; T U B B$, tubulin $\beta$ class I; UBE2C, ubiquitin conjugating enzyme E2 C; UCP2, uncoupling protein 2 .

these conditions was 863 (Fig. 2A). The total number of genes exhibiting statistically significant $(\mathrm{P}-\operatorname{adj}<0.01)$ downregulation
Table II. Genes upregulated or downregulated in interferon $\gamma$ (IFN- $\gamma$ ) or etoposide (ETO)-treated MDA-MB-231 cells in which PDIAl gene expression was silenced compared to PDIA1 expressing IFN- $\gamma$ - or ETO-treated MDA-MB-231 cells.

MDA-MB-231 cells

\begin{tabular}{ll} 
Upregulated & Downregulated \\
\hline HSP90B1 & CHCHD3 \\
IGFBP3 & PTPRJ \\
LAPTM5 & VMA21 \\
RNF213 & XIAP \\
SYNE1 &
\end{tabular}

PDIA1, protein disulfide isomerase A1; $C H C H D 3$, coiled-coil-he lix-coiled-coil-helix domain containing 3; HSP90B1, heat shock protein $90 \beta$ family member 1 ; IGFBP3, insulin like growth factor binding protein 3 ; LAPTM5, lysosomal protein transmembrane 5; $P T P R J$, protein tyrosine phosphatase receptor type $\mathrm{J} ; R N F 213$, ring finger protein 213; $S Y N E 1$, spectrin repeat containing nuclear envelope protein 1; VMA21, vacuolar ATPase assembly factor; XIAP, $\mathrm{X}$-linked inhibitor of apoptosis.

in IFN- $\gamma$-treated MCF-7 cells in which PDIAl gene expression had been silenced compared with IFN- $\gamma$-treated MCF-7 cells transfected with scramble siRNA was 773 , and the total number of genes upregulated under these conditions was 919 (Fig. 2B). The total number of genes exhibiting statistically significant downregulation in ETO-treated MDA-MB-231 cells in which PDIAl gene expression had been silenced compared with ETO-treated MDA-MB-231 cells transfected with scramble siRNA was 55, whereas the total number of genes upregulated in these cells under the same conditions was 27 (Fig. 2C). In the IFN- $\gamma$-treated MDA-MB-231 cells in which PDIAl gene expression had been silenced compared with IFN- $\gamma$-treated MDA-MB-231 cells transfected with scramble siRNA the total number of the downregulated genes was 11, whereas the total number of genes upregulated in these cells under the same conditions was 27 (Fig. 2D). The numbers of upregulated and downregulated genes are presented in Fig. 2E and F, respectively.

Clinical significance of the genes modulated in IFN- $\gamma$-or ETO-treated and PDIA1-silenced MCF-7 cells. To shed light on the clinical significance of the aforementioned findings, KM curves for the upregulated or downregulated genes in the PDIA1-silenced compared with the PDIA1-expressing and either IFN- $\gamma$ - or ETO-treated MCF-7 and MDA-MB-231 cells were plotted in the patients with ER $\alpha$-positive and ER $\alpha$-negative breast cancer, respectively, as described in the summary of the experimental design (Fig. 3). The upregulated or downregulated genes in MCF-7 cells under the conditions described above that exhibited statistically significant $(\mathrm{P}<0.05)$ $\mathrm{KM}$ results are shown in Table I. The KM curves plotted for these genes for ER $\alpha$-positive patients are shown in Fig. 4A-E. High expression of aurora kinase-A $(A U R K A)$, mitotic checkpoint serine/threonine-protein kinase BUB1 (BUB1), cyclin-B2 


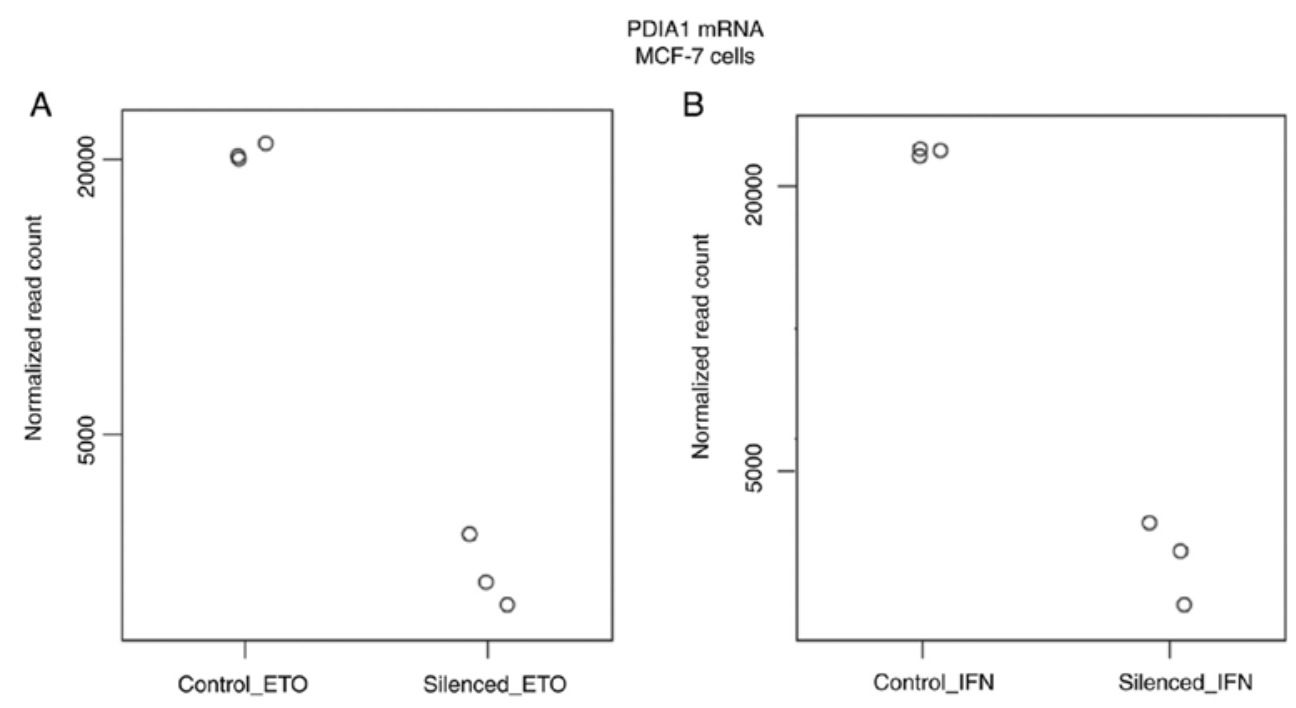

MDA-MB-231 cells
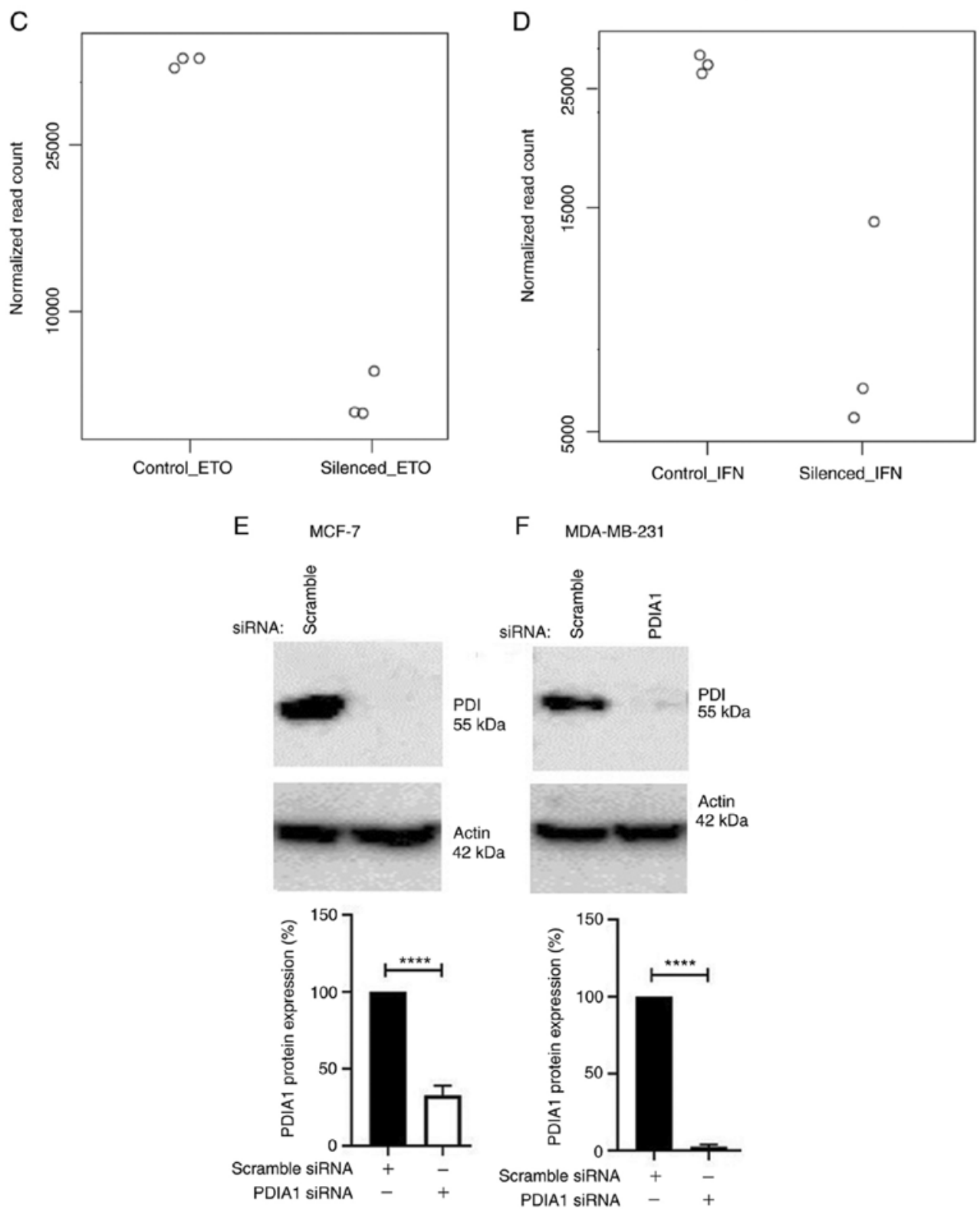

Figure 1. Total mRNA obtained from MCF-7 (A and B) or MDA-MB-231 (C and D) cells transfected with either scramble or specific siRNA to silence PDIA1 gene expression and treated with either etoposide (ETO) (A and C) or interferon $\gamma$ (IFN- $\gamma$ ) (B and D). PDIA1, protein disulfide isomerase A1 protein levels in scramble or PDIA1 siRNA transfected MCF-7 (E) or MDA-MB-231 (F) cells. The plots at the bottom of the figure indicate the transfection efficiency for the PDIA1-siRNA transfected compared to that for the scramble siRNA transfected cells. The data represent the mean of three independent experiments and the error bars represent mean \pm SEM. ${ }^{* * * *} \mathrm{P}<0.001$. PDIA1, protein disulfide isomerase A1. 

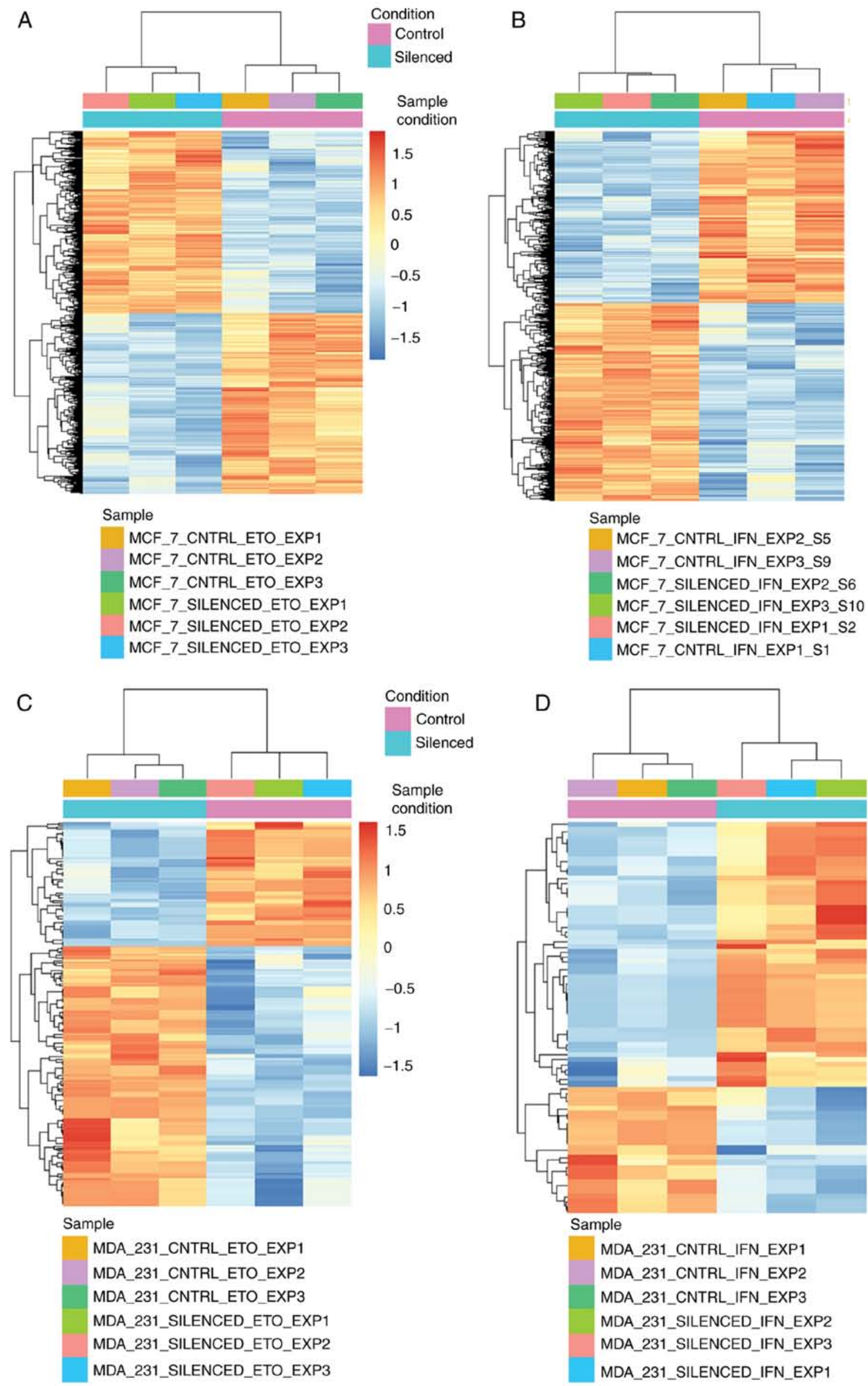

Figure 2. Continued. 

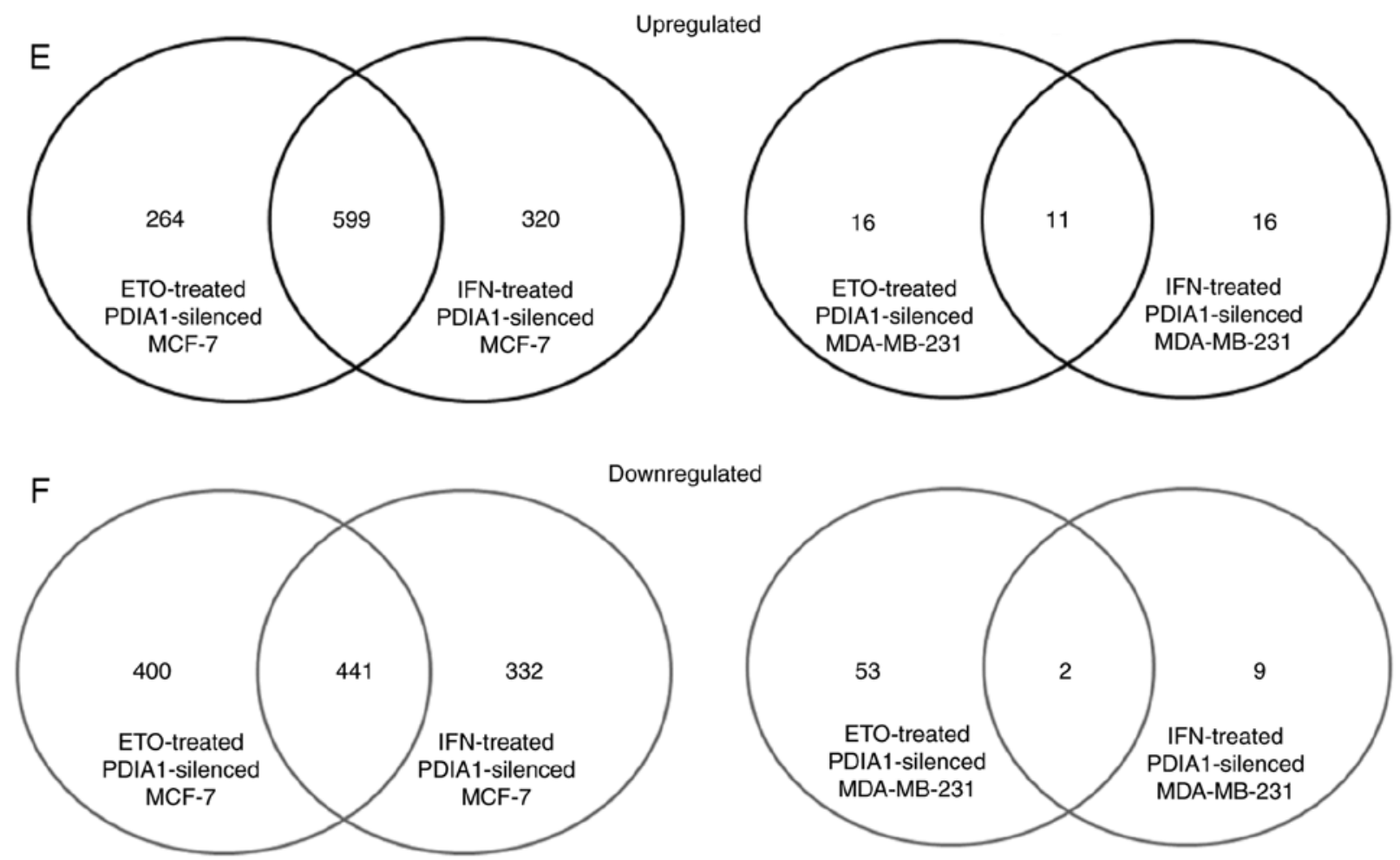

Figure 2. Genes upregulated or downregulated in PDIA1 siRNA-transfected compared to scramble transfected MCF-7 (A and B) or MDA-MB-231 (C and D) and treated with etoposide (ETO) (A and C) or interferon $\gamma(\mathrm{IFN}-\gamma)(\mathrm{B}$ and D). Number of genes upregulated (E) or downregulated (F) in ETO- or IFN- $\gamma$-treated and PDIA1-silenced compared to ETO- or IFN- $\gamma$-treated and scramble-transfected MCF-7 or MDA-MB-231 breast cancer cells. PDIA1, protein disulfide isomerase A1.

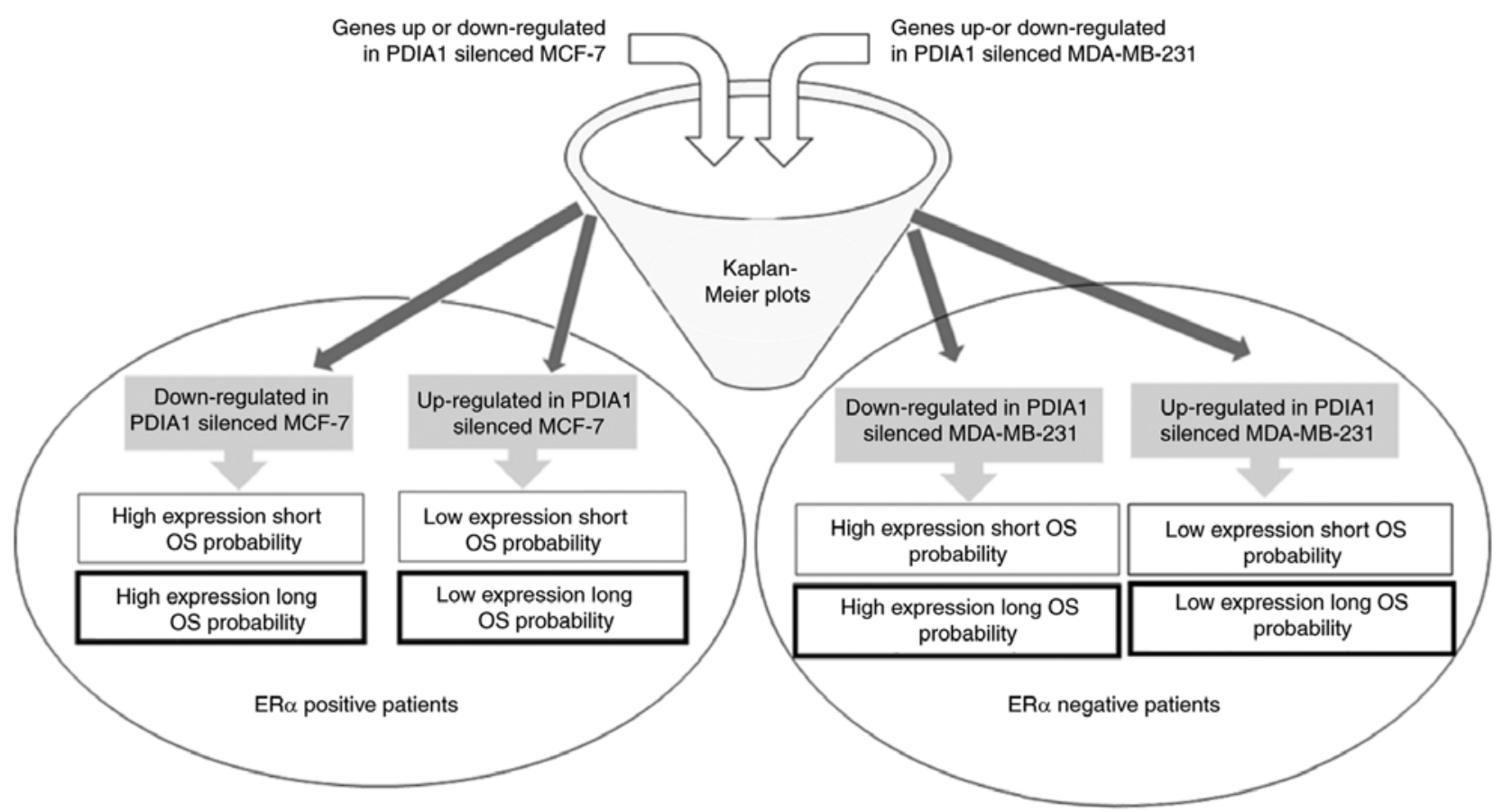

Figure 3. Schematic presentation of the experimental design followed in the study. PDIA1, protein disulfide isomerase A1; OS, overall survival; ER, estrogen receptor.

(CCNB2), cell division cycle 25C (CDC25A) (Fig. 4A), transcription factor E2F8 (E2F8), junD proto-oncogene (JUND), kinesin family member 11 (KIF11), L1 cell adhesion molecule (LICAM) (Fig. 4B), melanoma antigen gene D1 (MAGEDI), midkine $(M D K)$, pleckstrin homology-like domain family $\mathrm{A}$ member 2 (PHLDA2), membrane-associated tyrosine- and threonine kinase 1 (PKMYT1) (Fig. 4C), peroxiredoxin-2 $(P R D X 2)$, protein tyrosine phosphatase receptor type $\mathrm{S}$ 

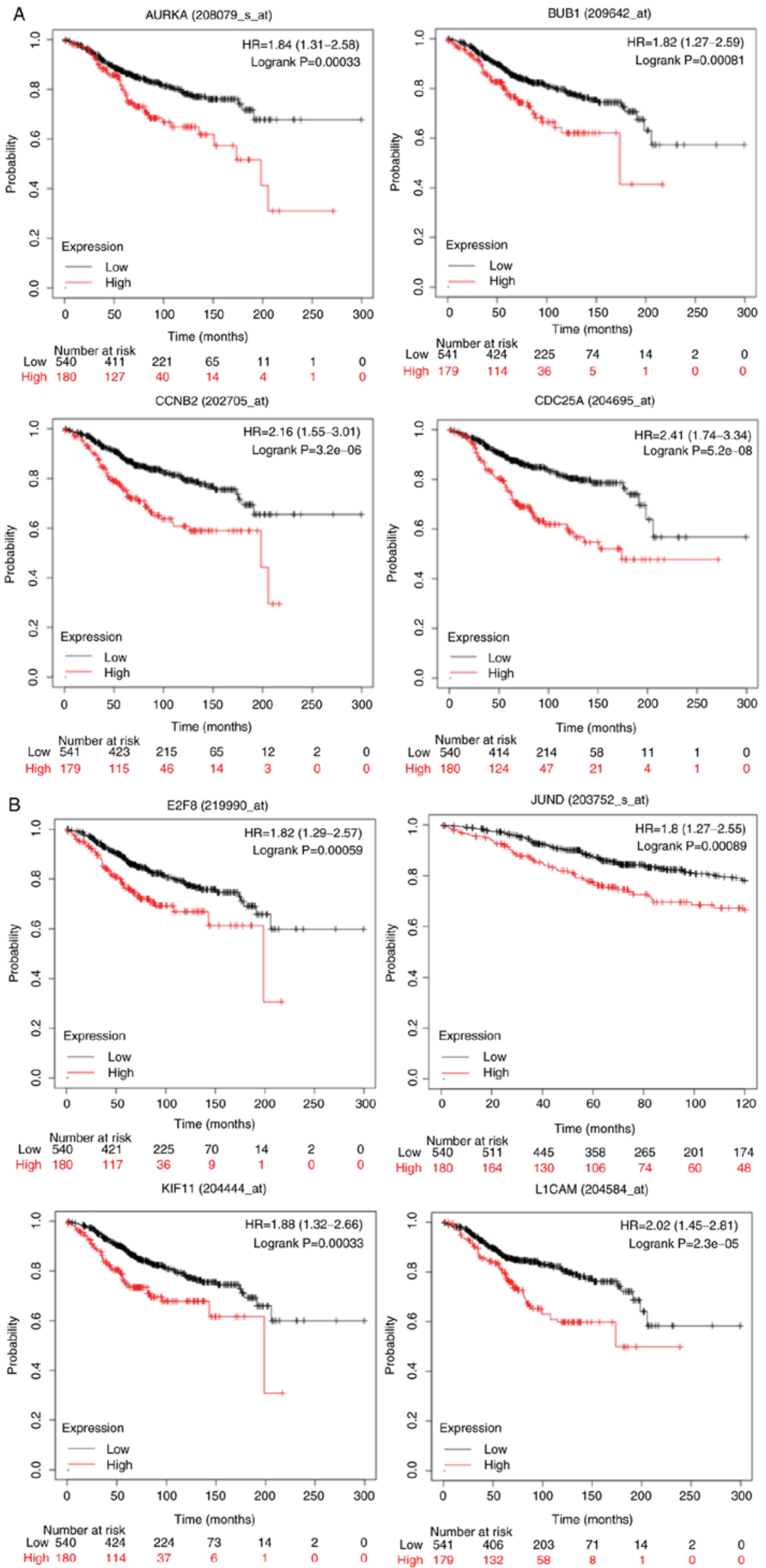

Figure 4. Continued. 

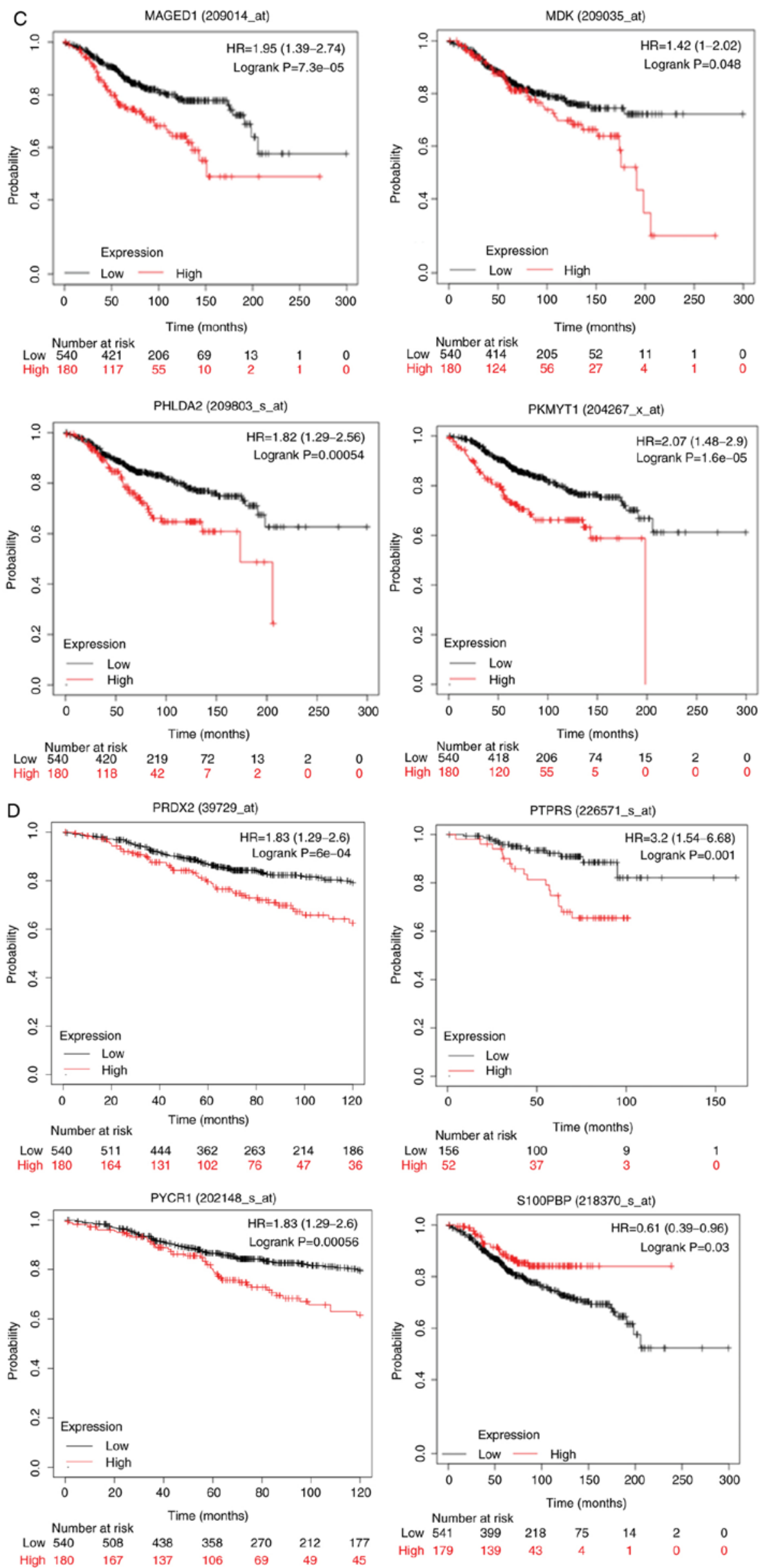

Figure 4. Continued. 

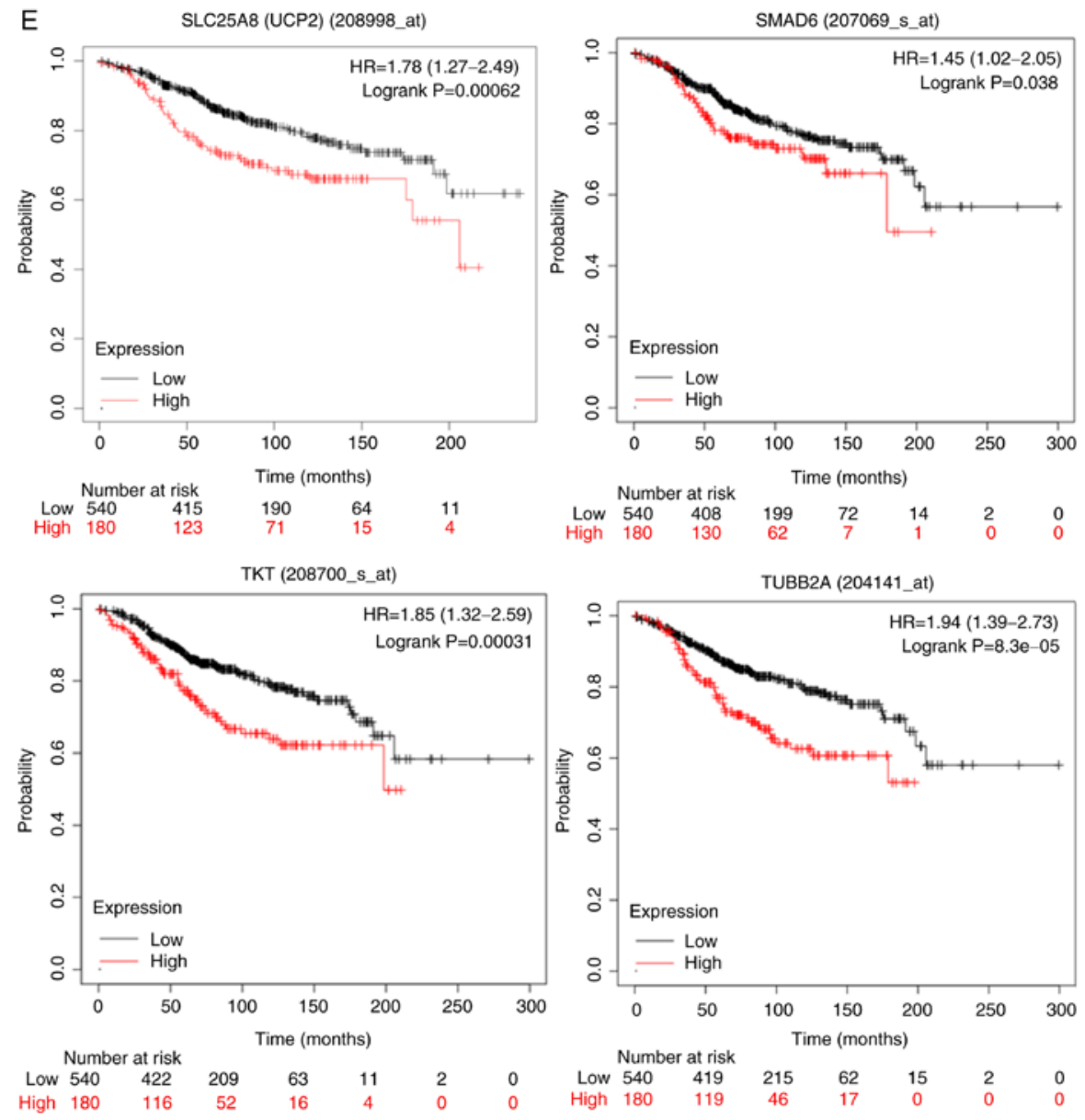

Figure 4. (A-E) Kaplan-Meir survival curves in ER $\alpha$-positive breast cancer patients for genes upregulated or downregulated in the absence of PDIA1 in etoposide (ETO)- or interferon $\gamma($ IFN- $\gamma$ )-treated MCF-7 breast cancer cells exhibiting statistically significant OS probability in patients with ER $\alpha$-positive breast cancer. PDIA1, protein disulfide isomerase A1; OS, overall survival; ER, estrogen receptor.

(PTPRS), pyrroline-5-carboxylate reductase 1 (PYCRI) (Fig. 4D), uncoupling protein 2 (UCP2), SMAD family member 6 (SMAD6), transketolase (TKT) and tubulin $\beta 2 \mathrm{~A}$ class IIa (TUBB2A) (Fig. 4E) genes was associated with statistically significant $(\mathrm{P}<0.05)$ shorter OS probability in the patients with ER $\alpha$-positive breast cancer. On the other hand, high expression of the S100P-binding protein $($ S100PBP) gene was associated with statistically significant $(\mathrm{P}<0.05)$ longer OS probability when comparing the 75th quartile with the 25th quartile in KM plotter in patients with ER $\alpha$-positive breast cancer (Fig. 4D).

To explore whether PDIAl gene expression in patients with ER $\alpha$-positive breast cancer was correlated with the upregulated or downregulated genes in either IFN- $\gamma$ - or ETO-treated PDIA1-silenced MCF-7 cells, the cBioPortal bioinformatics tool was used to investigate the Pearson correlation coefficient between PDIAI mRNA levels and that of the genes shown in Table I. This investigation was carried out by analyzing the data provided in the Breast Cancer (SMC 2018) database using the mRNA expression z-scores relative to all samples (RNA seq TPM, 168 samples) option. Positive correlations were observed between PDIAl gene expression and that of AURKA, $C D C 25 A$, centromere protein $\mathrm{F}(C E N P F)$, cytoskeletonassociated protein 5 (CKAP5), E2F8, extra spindle pole bodies like 1, separase (ESPL1), flap structure-specific endonuclease 1
(FEN1), G2 and S phase-expressed protein 1 (GTSE1), JUND, KIF11, kinesin-like protein KIF20A (KIF20A), MAGED1, $M D K, P K M Y T 1, P R D X 2, P T P R S, P Y C R 1$, RAN binding protein 1 (RANBPI), S10OPBP, SMAD6, transforming acidic coiled-coil-containing protein 3 (TACC3), TKT, thyroid hormone receptor interactor 13 (TRIPI3), tubulin b class 1 $(T U B B)$, ubiquitin-conjugating enzyme E2 C (UBE2C) and $U C P 2$ genes. In other words, in the presence of PDIA1, the expression of these genes would be upregulated, whereas in the absence of PDIA1, the expression of these genes would be downregulated in patients with ER $\alpha$-positive breast cancer. Among these genes, the correlation between PDIAl (shown as $P 4 H B$ ) gene expression and that of the CKAP5, FEN1, PYCR1, TACC3, TKT and TUBB genes exhibited higher Pearson correlation coefficients (Fig. 5).

Positive correlations between PDIAI gene expression and that of MAGED1, MDK, PRDX2, PTPRS, PYCR1, SMAD6, $T K T$ and $U C P 2$ genes were found, which were demonstrated to be upregulated in the PDIA1-silenced MCF-7 cells (Table I), thus indicating that in the presence of PDIA1 in patients with ER $\alpha$-positive breast cancer these genes would be downregulated. According to the KM plots, the downregulation of MAGED1, MDK, PRDX2, PTPRS, PYCR1, SMAD6, TKT and UCP2 mRNA levels was associated with higher OS probability in the patients with ER $\alpha$-positive breast 

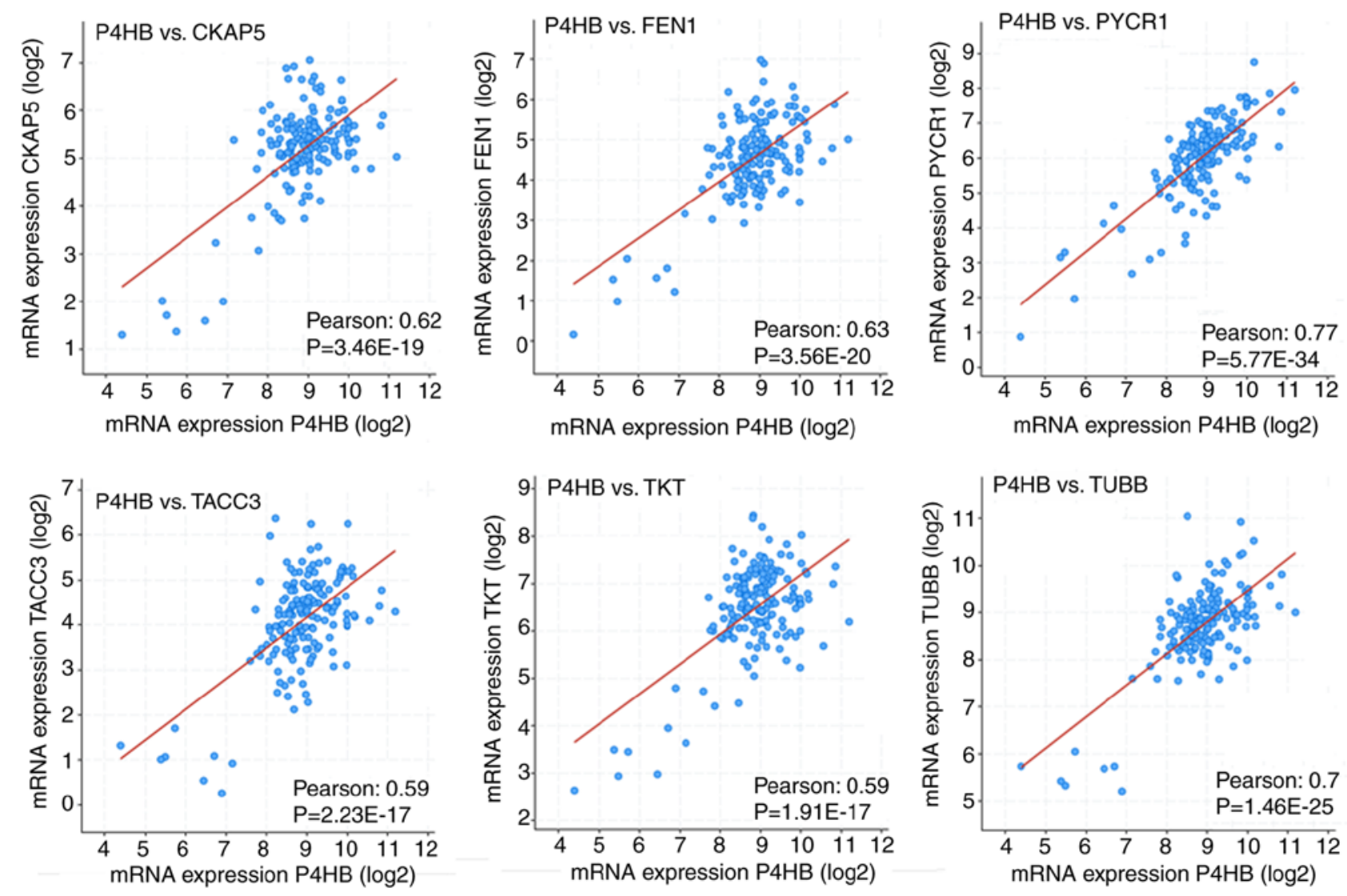

Figure 5. Pearson correlation coefficient between PDIA1 (P4HB) mRNA levels and that of CKAP5, FEN1, PYCR1, TACC3, TKT and TUBB genes. CKAP5, cytoskeleton associated protein 5; FEN1, flap structure-specific endonuclease 1; PYCR1, pyrroline-5-carboxylate reductase 1; TACC3, transforming acidic coiled-coil containing protein 3; TKT, transketolase; TUBB, tubulin $\beta$ class I.

cancer (Fig. 4). This suggested that PDIA1 can associate with MAGED1, MDK, PRDX2, PTPRS, PYCR1, SMAD6, TKT and $U C P 2$ to induce anti-oncogenic effects in patients with ER $\alpha$-positive breast cancer. To explore the pathways involved in the PDIA1-mediated anti-oncogenic effects in patients with ER $\alpha$-positive breast cancer, the Metascape bioinformatics tool was employed (51). The results of this analysis showed that the pathways by which PDIA1 exerts tumor-suppressive effects include cell-substrate adhesion, regulation of growth and response to ROS (Table III).

Direct correlations between PDIAl gene expression and that of the AURKA, CDC25A, CENPF, CKAP5, E2F8, ESPL1, FEN1, GTSE1, JUND, KIF11, KIF20A, PKMYT1, RANBP1, $S 100 P B P, T A C C 3, T R I P 13, T U B B$ and $U B E 2 C$ genes were also observed, which were found to be downregulated in the PDIA1-silenced MCF-7 cells (Table I). This suggested that in the presence of PDIA1 in patients with ER $\alpha$-positive breast cancer these genes would be upregulated. The KM plots indicated that high levels of these genes were associated with shorter OS in patients with ER $\alpha$-breast cancer (Fig. 4A-C and E), apart from S100PBP (Fig. 4D). Therefore, the association of PDIA1 with these genes is a potential route by which PDIA1 exerts oncogenic effects in patients with ER $\alpha$-positive breast cancer. The pathways affected by the networks formed by these genes were investigated using the Metascape bioinformatics tool and they included control of cell cycle transition to the mitotic phase as well as regulation of the cell cycle checkpoints (Table IV).
Clinical significance of the genes modulated in IFN- $\gamma$-or ETO-treated and PDIA1-silenced MDA-MB-231 cells. Similar analysis to that described for the MCF-7 cells was carried out for the upregulated or downregulated genes in the IFN- $\gamma$ or ETO-treated MDA-MB-231 cells with PDIA1 silenced compared with IFN- $\gamma$ - or ETO-treated cells transfected with scramble siRNA that exhibited statistically significant $(\mathrm{P}<0.05)$ $\mathrm{KM}$ results are shown in Table II, and the KM curves plotted for these genes in ER $\alpha$-negative patients are presented in Fig. 6. KM survival curves were plotted for the upregulated or downregulated genes in MDA-MB-231 cells under various oxidative stress conditions in patients with ER $\alpha$-negative breast cancer (Fig. 6A and B). High expression of the coiled-coil-helix -coiled-coil-helix domain containing 3 ( $\mathrm{CHCHD} 3)$, heat shock protein $90 \beta$ family member 1 (HSP90B1), lysosomal-associated transmembrane protein 5 (LAPTM5) (Fig. 6A), protein tyrosine phosphatase receptor type $\mathrm{J}(P T P R J)$, ring finger protein 213 (RNF213), spectrin repeat containing nuclear envelope protein 1 (SYNE1), vacuolar ATPase assembly factor VMA21 (VMA21) and X-linked inhibitor of apoptosis (XIAP) (Fig. 6B) genes was associated with statistically significant $(\mathrm{P}<0.05)$ longer $\mathrm{OS}$ in the patients with ER $\alpha$-negative breast cancer. On the other hand, high gene expression of insulin-like growth factor-binding protein 3 (IGFBP3) was associated with lower OS probability in these patients (Fig. 6A).

The Pearson correlation coefficients between PDIAl gene expression and the upregulate or downregulated genes in the PDIA1-silenced MDA-MB-231 cells under oxidative stress 
Table III. Gene Ontology pathways and gene networks through which PDIA1 confers anti-carcinogenic effects to patients with ER $\alpha$-positive breast cancer.

\begin{tabular}{lllllc}
\hline & Term & \multicolumn{1}{c}{ Description } & Hits & Log P & Log (q-value) \\
\hline 1 & GO:0031589 & Cell-substrate adhesion & SMAD6 & -6.61 & -2.26 \\
2 & GO:0040008 & Regulation of growth & $P T P R S, T K T$ & -3.93 & -0.48 \\
3 & GO:0000302 & Response to reactive oxygen species & PYCR1, PRDX2, UCP2 & -3.98 & -0.48 \\
\hline
\end{tabular}

SMAD6, SMAD family member 6; PTPRS, protein tyrosine phosphatase receptor type S; TKT, transketolase; PYCR1, pyrroline-5-carboxylate reductase $1 ; P R D X 2$, peroxiredoxin 2; $U C P 2$, uncoupling protein 2.

Table IV. Gene Ontology pathways and gene networks through which PDIAl confers pro-oncogenic effects to ER $\alpha$-positive breast cancer patients.

\begin{tabular}{|c|c|c|c|c|c|}
\hline & Term & Description & Hits & $\log P$ & $\log (q-v a l u e)$ \\
\hline 1 & GO:0010564 & $\begin{array}{l}\text { Regulation of cell } \\
\text { cycle process }\end{array}$ & $\begin{array}{l}\text { AURKA, CDC25A, CENPF, CKAP5, E2F8, ESPL1, } \\
\text { FEN1, GTSE1, KIF11, KIF20A, PKMYT1, TACC3, } \\
\text { TRIP13, TUBB, UBE2C }\end{array}$ & -42.08 & -37.73 \\
\hline 2 & GO:0044770 & $\begin{array}{l}\text { Cell cycle phase } \\
\text { transition }\end{array}$ & $\begin{array}{l}\text { AURKA, CDC25A, CENPF, CKAP5, E2F8, ESPL1, } \\
\text { GTSE1, PKMYT1, TACC3, TRIP13, TUBB }\end{array}$ & -37.03 & -33.15 \\
\hline 3 & GO:0007346 & $\begin{array}{l}\text { Regulation of mitotic } \\
\text { cell cycle }\end{array}$ & $\begin{array}{l}\text { AURKA, CDC25A, CENPF, CKAP5, E2F8, ESPL1, } \\
\text { GTSE1, KIF11, PKMYT1, RANBP1, TACC3, } \\
\text { TRIP13, TUBB, UBE2C }\end{array}$ & -25.16 & -21.80 \\
\hline 4 & GO:0000075 & Cell cycle checkpoint & AURKA, CENPF, E2F8, GTSE1, TRIP13 & -16.50 & -13.66 \\
\hline 5 & GO:0044839 & $\begin{array}{l}\text { Cell cycle } \mathrm{G} 2 / \mathrm{M} \\
\text { phase transition }\end{array}$ & $\begin{array}{l}\text { AURKA, CDC25A, CENPF, CKAP5, GTSE1, } \\
\text { PKMYT1, TUBB }\end{array}$ & -18.57 & -15.61 \\
\hline
\end{tabular}

$A U R K A$, aurora kinase A; $C D C 25 C$, cell division cycle 25C; $C E N P F$, centromere protein F; $C K A P 5$, cytoskeleton associated protein 5; $E 2 F 8$, E2F transcription factor 8; ESPL1, extra spindle pole bodies like 1, separase; FEN1, flap structure-specific endonuclease 1; GTSE1, G2 and S-phase expressed 1; KIF11, kinesin family member 11; KIF20A, kinesin family member 20A; PKMYT1, protein kinase, membrane associated tyrosine/threonine $1 ; R A N B P 1$, RAN binding protein 1 ; TACC3, transforming acidic coiled-coil containing protein 3; TRIP13, thyroid hormone receptor interactor 13; TUBB, tubulin $\beta$ class I; $U B E 2 C$, ubiquitin conjugating enzyme E2 C; $U C P 2$, uncoupling protein 2.

conditions (Table II) were investigated using the cBioPortal platform. To carry out this analysis, only samples originating from patients with ER $\alpha$-negative breast cancer were included, but no statistical significance or data were available to manually calculate the correlation between PDIAl gene expression and these genes in the patients with ER $\alpha$-negative breast cancer. Thus, it was hypothesized that the Pearson correlation coefficients between PDIAl gene expression with that of the genes shown in Table II were positive, meaning that in the presence of PDIA1, HSP9OB1, IGFBP3, LAPTM5, RNF213 and $S Y N E 1$ genes would be downregulated, while $C H C H D 3$, PTPRJ, VMA21 and XIAP would be upregulated, in patients with $E R \alpha$-negative breast cancer.

Direct associations between PDIA1 and CHCHD3, PTPRJ, $V M A 21$ and XIAP indicated that these genes can induce tumor-suppressive effects in patients with ER $\alpha$-negative breast cancer since the KM plots in these patients showed that the high expression of these genes was associated with longer OS (Fig. 6A and B). PDIA1 would mediate tumor-suppressive effects in patients with ER $\alpha$-negative breast cancer patients via IGFBP3 as well since this gene in the presence of PDIA1 is downregulated (Table II) and the KM plot in these patients showed that low expression of IGFBP3 was associated with longer OS (Fig. 6A). In addition, direct association between PDIA1 and HSP90B1, LAPTM5, RNF213 and SYNE1 gene expression suggested that these genes confer oncogenic effects to patients with ER $\alpha$-negative breast cancer since the KM plots for these patients indicated that low expression was associated with lower OS probability (Fig. 6A and B).

The Metascape bioinformatics tool was used to identify the pathways affected by the genes modulated by PDIA1 to confer anti- or pro-carcinogenic effects in patients with ER $\alpha$-negative breast cancer. This analysis revealed that PDIA1 may exert tumor-suppressive effects in patients with ER $\alpha$-negative breast cancer by interfering with the NF-kB signaling pathway (XIAP), glycolysis (IGFBP3), mitochondrial biogenesis $(C H C H D 3)$ and negative regulation of cell migration (IGFBP3, P4HB, PTPRJ) (Table V). Metascape analysis also showed that PDIA1 may trigger pro-oncogenic effects by forming signaling networks with calmodulin-3 (CALM3), HSP90B1, LAPTM5 and RNF213 genes, which could affect pathways such as the adaptive immune system and cytokine signalling in the immune system, as well as activating signal transduction in the immune response (Table VI). 
A

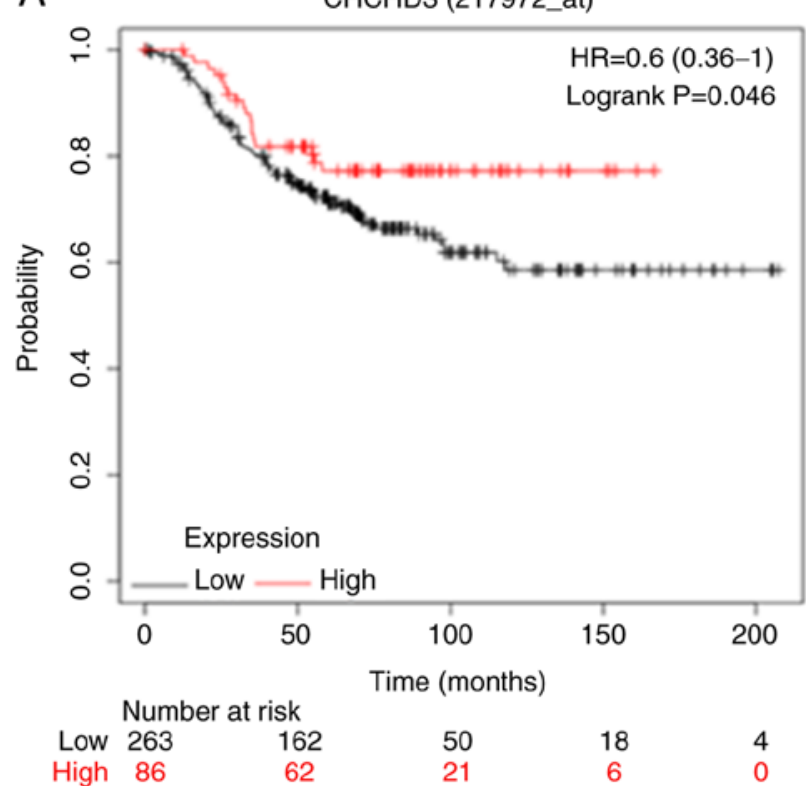

IGFBP3 (210095_s_at)

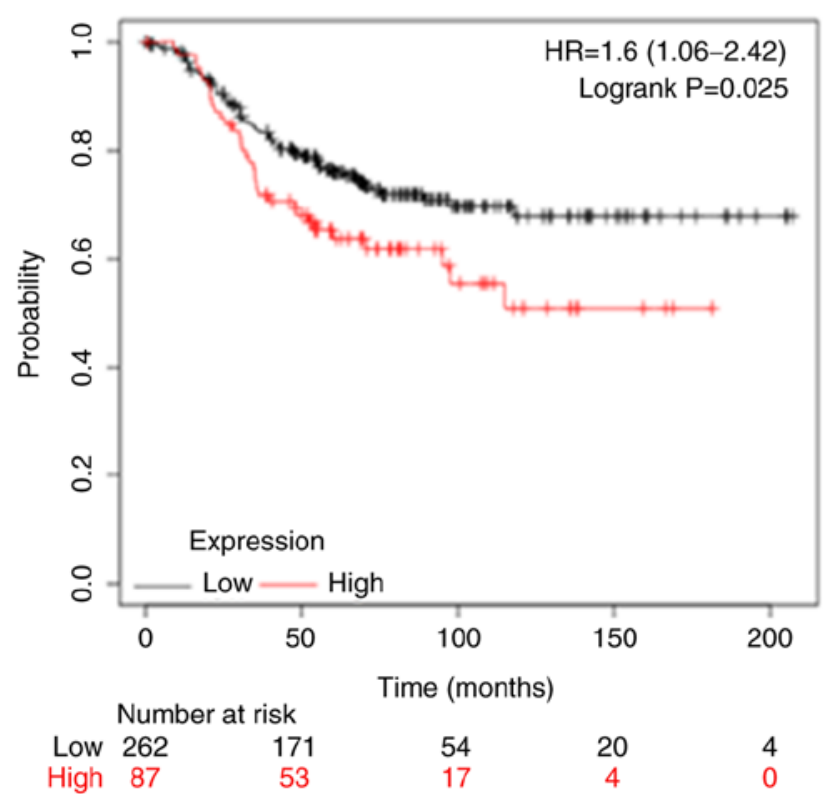

HSP90B1 (200599_s_at)

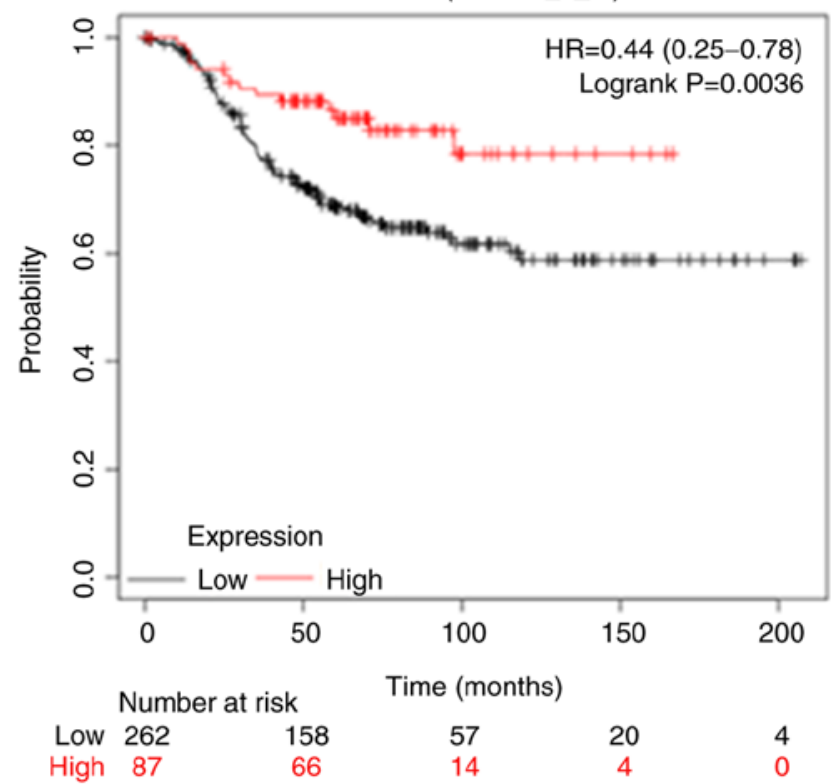

LAPTM5 (201721_s_at)

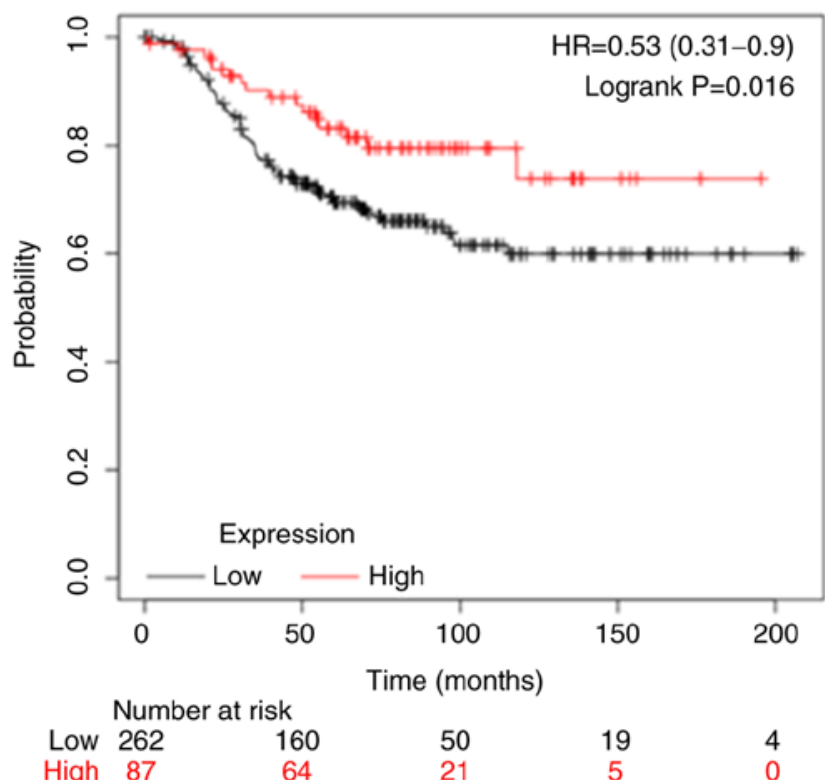

Figure 6. Continued.

Drugs targeting genes involved in pathways conferring oncogenic activity in breast cancer patients. To investigate whether approved or experimental drugs targeting the genes involved in the pathways conferring oncogenic activity in the patients with ER $\alpha$-positive (Table VII) or ER $\alpha$-negative (Table VIII) breast cancer, the genes associated with PDIA1 and its oncogenic effects were investigated in each subgroup of patients with breast cancer using the DRUGSURV (52) bioinformatics tool. This investigation revealed that in the patients with ER $\alpha$-positive breast cancer, drugs targeting the function of the AURKA, FEN1, KIF11, PKMYT1 and TUBB genes, which are involved in the regulation of cell cycle progression, would be selectively effective for this group of patients. On the other hand, drugs targeting the function of the HSP9OBI gene, which is involved in the regulation of toll-like receptor translocation through the endoplasmic reticulum to the plasma membrane (53), would be preferential for the patients with $\mathrm{ER} \alpha$-negative breast cancer.

\section{Discussion}

In our previous study, we described the effect of protein disulfide isomerase A1 (PDIA1) silencing on reactive oxygen species (ROS) generation, glutathione (GSH) levels, mitochondrial membrane potential, adenosine triphosphate (ATP) production and human leukocyte antigen G (HLA-G) surface levels in MCF-7 and MDA-MB-231 cells treated with etoposide or interferon (IFN)- $\gamma$ in the presence or absence of PDIA1 (4). We and others reported that PDIA1 exerts differential effects in estrogen receptor (ER) $\alpha$-positive vs. 
$\mathrm{B}$

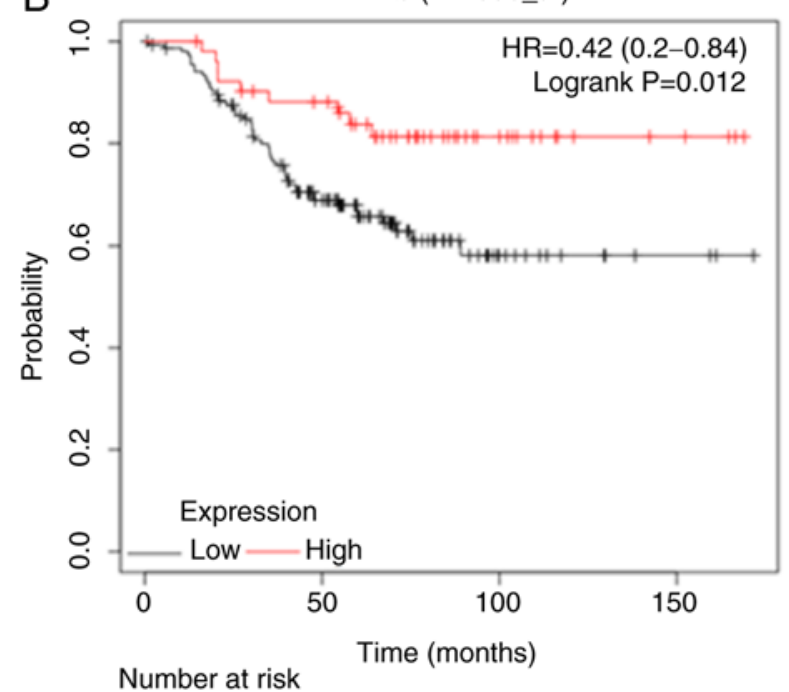

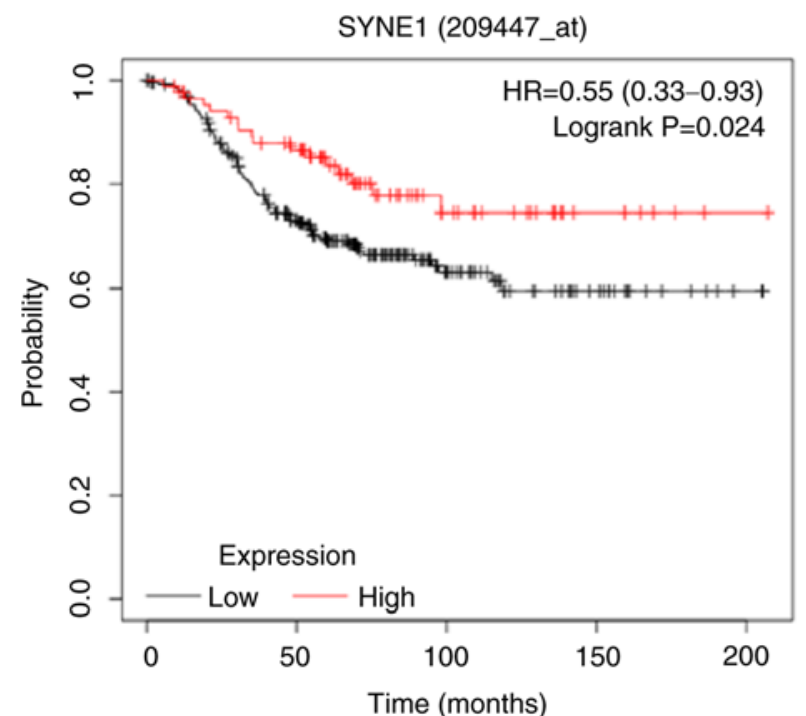

\begin{tabular}{|c|c|c|c|c|c|}
\hline \multicolumn{6}{|c|}{ risk } \\
\hline Low & 262 & 158 & 50 & 18 & \\
\hline High & 87 & 66 & 21 & 6 & \\
\hline
\end{tabular}
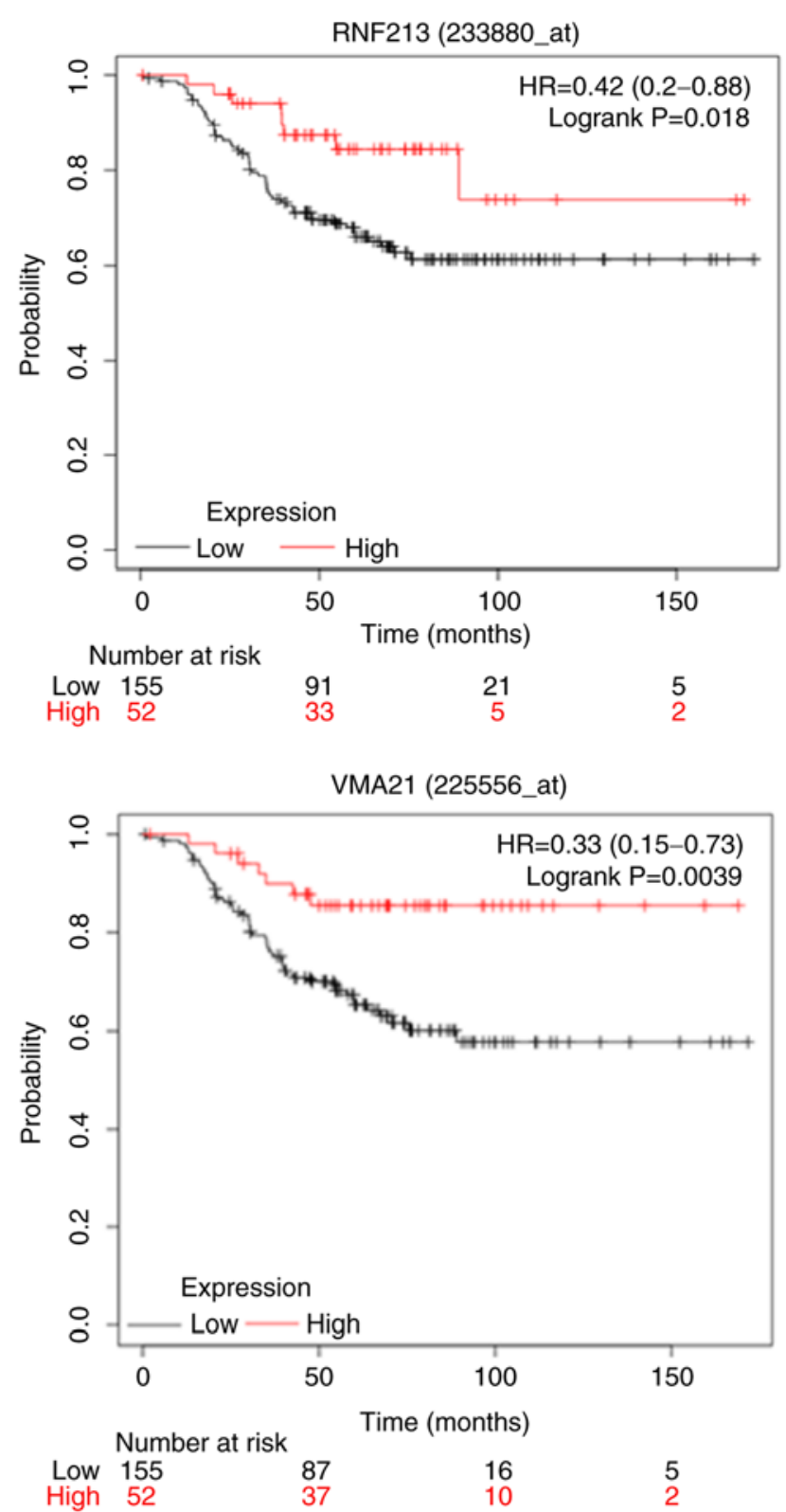

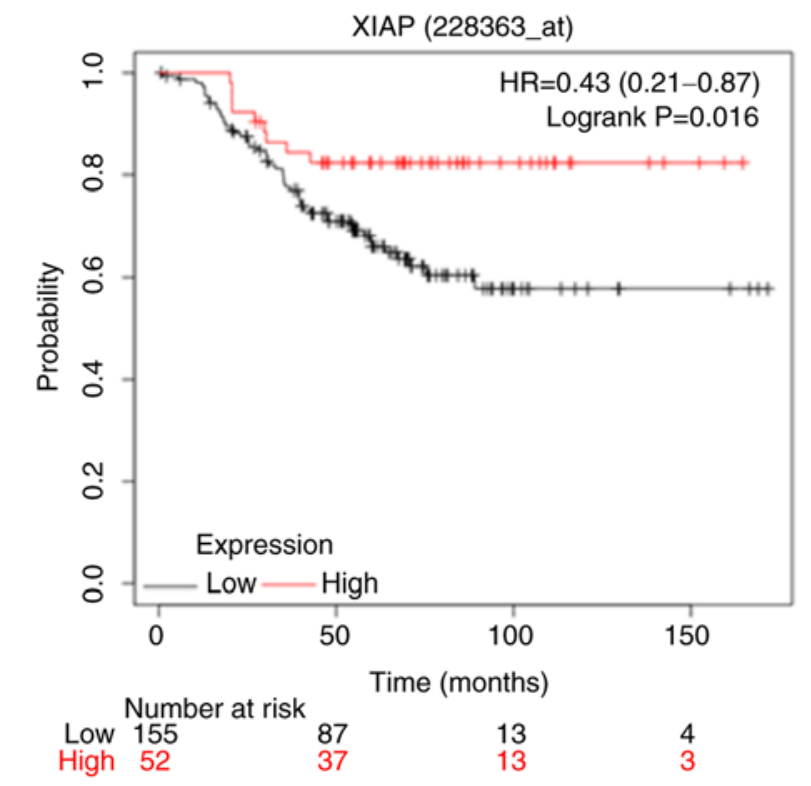

Figure 6. (A and B) Kaplan-Meir survival curves in patients with ER $\alpha$-negative breast cancer for genes upregulated or downregulated in PDIA1-silenced and etoposide (ETO)- or interferon $\gamma($ IFN- $\gamma$ )-treated MDA-MB-231 breast cancer cells. PDIA1, protein disulfide isomerase A1; ER, estrogen receptor. 
Table V. Gene Ontology pathways and gene networks through which PDIAl confers anti-oncogenic effects to ER $\alpha$-negative breast cancer patients.

\begin{tabular}{|c|c|c|c|c|c|}
\hline & Term & Description & Hits & $\log \mathrm{P}$ & $\log (q-v a l u e)$ \\
\hline 1 & hsa04064 & $\mathrm{NF}-\kappa \mathrm{B}$ signaling pathway & $X I A P$ & -16.64 & -3.35 \\
\hline 2 & GO:0006006 & Glucose metabolic process & $I G F B P 3$ & -8.6 & -8.6 \\
\hline 3 & R-HSA-1592230 & Mitochondrial biogenesis & CHCHD3 & -2.71 & -2.71 \\
\hline 4 & GO:0030336 & Negative regulation of cell migration & $I G F B P 3, P T P R J$ & -1.90 & -0.96 \\
\hline 5 & GO:0030155 & Regulation of cell adhesion & $P 4 H B, P T P R J$ & -8.96 & -1.03 \\
\hline
\end{tabular}

CHCHD3, coiled-coil-helix-coiled-coil-helix domain containing 3; IGFBP3, insulin like growth factor binding protein 3; $P 4 H B$, prolyl 4-hydroxylase subunit $\beta$; PTPRJ, protein tyrosine phosphatase receptor type $\mathrm{J} ; X I A P, \mathrm{X}$-linked inhibitor of apoptosis.

Table VI. Gene Ontology pathways and gene networks through which PDIAl confers pro-oncogenic effects to ER $\alpha$-negative breast cancer patients.

\begin{tabular}{lllllc}
\hline \multicolumn{1}{c}{ Term } & \multicolumn{1}{c}{ Description } & \multicolumn{1}{c}{ Hits } & Log P & Log (q-value) \\
\hline 1 & R-HSA-1280218 & Adaptive immune system & CALM3, RNF213 & -4.22 & -0.94 \\
2 & R-HSA-1280215 & Cytokine signaling in immune system & $H S P 90 B 1$ & -2.91 & -0.16 \\
3 & GO:0006874 & Cellular calcium ion homeostasis & CALM3, HSP90B1 & -3.52 & -0.50 \\
4 & GO:0002757 & Immune response-activating signal transduction & HSP90B1, LAPTM5 & -2.86 & -0.25 \\
\hline
\end{tabular}

$C A L M 3$, calmodulin 3; RNF213, ring finger protein 213; HSP90B1, heat shock protein $90 \beta$ family member 1 ; LAPTM5, lysosomal protein transmembrane 5 .

Table VII. Approved drugs directly targeting genes associated with PDIA1 that confer pro-oncogenic effects to ER $\alpha$-positive breast cancer patients.

\begin{tabular}{ll}
\hline Gene symbol & $\begin{array}{c}\text { Drugs targeting genes associated with PDIA1 } \\
\text { with potential anti-carcinogenic activity in } \\
\text { ER } \alpha \text {-positive breast cancer patients. }\end{array}$ \\
\hline AURKA & $\begin{array}{l}\text { Phosphonothreonine, alisertib, cenisertib, } \\
\text { enzastaurin, fostamatinib }\end{array}$ \\
FEN1 & $\begin{array}{l}\text { Idarubicin, quinacrine, masoprocol, } \\
\text { mitoxantrone }\end{array}$ \\
KIF11 & $\begin{array}{l}\text { Monastrol } \\
\text { PKMYT1 }\end{array}$ \\
DUBB & $\begin{array}{l}\text { Colchicine, vinblastine, albendazole, } \\
\text { podofilox, vinorelbine, vincristine }\end{array}$
\end{tabular}

AURKA, aurora kinase A; FEN1, flap structure-specific endonuclease $1 ; K I F 11$, kinesin family member $11 ; P K M Y T 1$, protein kinase, membrane associated tyrosine/threonine $1 ; T U B B$, tubulin $\beta$ class I.

triple-negative breast cancer (TNBC) cells $(4,10)$. These effects in the ER $\alpha$-positive cells are mediated possibly through the physical interaction between PDIA1 and the ER $\alpha$ and the regulation of the transcriptional activity of the receptor (26) whereas the impact of the PDIA1 in the ER $\alpha$-negative cells is mediated through estrogen-independent pathways. To solidify
Table VIII. Approved drugs targeting directly or indirectly genes associated with PDIAl that confer pro-oncogenic effects to ER $\alpha$-negative breast cancer patients.

Drugs targeting genes associated with PDIA1 with potential anti-carcinogenic

Gene symbol activity in ER $\alpha$-negative patients

HSP9OB1 Rifabutin

$H S P 90 B 1$, heat shock protein $90 \beta$ family member 1 .

our previous observations indicating the differential PDIA1 effects in a type and genetic background tumor-dependent mode (4) and taking into account the fact that PDIA1 exerts these differential effects functioning as a transcriptional co-modulator $(27,33,54)$, we silenced PDIA1 gene expression in ERo-positive MCF-7 and TNBC MDA-MB-231 cells and submitted total mRNA isolated from these cells to RNA-seq analysis. The RNAseq experiments were performed in PDIA1 siRNA or scramble transfected MCF-7 and MDA-MB-231 cells treated with either IFN- $\gamma$ or etoposide. A limitation of this study is that the PDIA1 mRNA expression levels in untreated MCF-7 and MDA-MB-231 transfected with scramble or PDIA1 siRNA were not analyzed. The results indicated that the number of genes that were upregulated or downregulated 
in the PDIA1-silenced MCF-7 cells was higher compared to that identified in the MDA-MB-231 cells suggesting that the main effects of PDIAI on gene expression were mediated by the activity of the ER $\alpha$ transcription factor whereas in the TNBC cells through other transcription factors associated with PDIA1 such as hypoxia-inducible factor $1 \alpha(\mathrm{HIF}-1 \alpha)(18)$, nuclear factor (erythroid-derived 2)-like 2 (NRF2) (32) and nuclear factor (NF)- $\kappa \mathrm{B}$ activity (27).

To overcome the limitation of the lack of patient recruitment in the present study, the clinical significance of the modified genes was investigated by plotting KM survival curves to identify whether high or low expression of each one of these genes affected the overall survival (OS) probability in ER $\alpha$-positive or ER $\alpha$-negative patients. Furthermore, the pathways that the modulated genes were involved in to confer anti-carcinogenic or pro-oncogenic effects were identified using bioinformatic tools and grouped into four categories. The first group included the genes that were downregulated in the PDIA1-silenced MCF-7 breast cancer cells and therefore upregulated in the presence of PDIA1 in the ER $\alpha$-positive breast cancer patients and their high expression was found to be associated with short survival probability; or downregulated in the PDIA1-silenced MCF-7 breast cancer cells and therefore upregulated in the presence of PDIA 1 in breast cancer patients and their high expression was found to be associated with long OS probability. The genes that were downregulated in the ER $\alpha$-positive breast cancer patients (upregulated in the PDIA1-silenced MCF-7 cells) and their low expression was associated with reduced OS; or downregulated in the ER $\alpha$-positive breast cancer patients (upregulated in the PDIA1-silenced MCF-7 cells) and their low expression was associated with long OS probability formed the second category. The same categories forming the third and fourth groups were created for the genes exerting negative or positive effects on the OS of ER $\alpha$-negative patients. Although several genes were found to be upregulated or downregulated in both the MCF-7 and MDA-MB-231 cells, the genes whose high expression resulted in statistically significant probability of short or long OS in the ER $\alpha$-positive or ER $\alpha$-negative patients were different.

To investigate the possibility that different gene networks in ER $\alpha$-positive vs. ER $\alpha$-negative breast cancer patients are associated with tumor-suppressive or oncogenic effects, we employed the Metascape bioinformatic tool (51). The results of this analysis indicated that the pathways induced to confer tumor-suppressive effects in the ER $\alpha$-positive patients are mainly cell-substrate adhesion (SMAD6) (55-57) regulation of growth $(P T P R S, T K T)(58,59)$ and the response to reactive oxygen species (PYCR1, PRDX2, UCP2) (60). Tumor-suppressive effects in the ER $\alpha$-negative breast cancer patients were found to be mediated by pathways related to positive regulation of cell death $(I G F B P 3)(61), \mathrm{NF}-\kappa \mathrm{B}$ signaling pathway (XIAP) (62), mitochondrial biogenesis (CHCHD3) (63) and negative regulation of cell migration (PTPRJ) (64).

The gene networks with which PDIA1 was associated to induce tumorigenesis in the ER $\alpha$-positive breast cancer patients regulate pathways controlling cell cycle progression (65). Aurora kinase-A (AURKA) gene amplification or mutations are common aberrations in breast cancer, especially in ER $\alpha$-positive breast carcinomas (66). Cyclin A2 (CCNA2) is overexpressed in various types of cancer including breast cancer reducing the OS of ER $\alpha$-positive breast cancer patients and induces resistance to tamoxifen treatment (67). The CDC25C phosphatase participates in the regulation of the cell cycle progression from the $\mathrm{G} 2$ to $\mathrm{M}$ phase by dephosphorylating and activating the cyclin B1/CDK1 complex. Overexpression of $\mathrm{Cdc} 25 \mathrm{~A}$ in breast carcinoma patients is associated with poor survival (68). The KIF11 gene is involved in the control of cell cycle progression by promoting centrosome separation and its high expression is associated with poor prognosis of breast cancer patients (69). Tubulin $\alpha$ la (TUBA1A) is one of three alpha-tubulin genes which are the major components of microtubules. Analysis of the expression profile of breast cancer tumors has indicated that TUBA1A is upregulated in tumor tissues compared to tumor-adjacent normal breast tissues (70).

The oncogenic activities of PDIA1 in ER $\alpha$-negative patients are exerted through its association with genes involved in the regulation of the immune response (HSP90B1, LAPTM5 $R N F 213$ ) (71-73). Aberrant regulation of gene expression of genes involved in modulating the immune response in breast tumors could lead to a low level of tumor infiltrating lymphocytes (TILs) and hence immune response evasion and breast cancer aggressiveness $(74,75)$. It should be noted that analysis of the correlation between PDIA1 gene expression and that of the genes upregulated or downregulated in the PDIA1-silenced MDA-MB-231 cells was not carried out because data for these genes were not available in the ER $\alpha$-negative patients or the Pearson correlation coefficient for those that data were available was not statistically significant.

To further investigate the possibility of differential targeting of the oncogenic pathways in ER $\alpha$-positive vs. ER $\alpha$-negative breast cancer patients, the existence of drugs targeting the genes implicated in oncogenic pathways were investigated using the DRUGSURV tool (52). The drugs targeting oncogenic pathways in the ER $\alpha$-positive patients include those that target cell cycle progression such as cenisertib, enzastaurin, and rostamatinib, whereas drugs targeting genes involved in immune response pathways such as rifabutin could be used for the treatment of ER $\alpha$-negative patients.

In conclusion, PDIA1 functions as a transcriptional cofactor regulating the transcriptional activity of the ER in ER $\alpha$-positive breast cancers and HIF- $1 \alpha, \mathrm{NRF} 2$ and NF- $\kappa \mathrm{B}$ activity in ER $\alpha$-negative breast cancers. The consequence of this is that diverse oncogenic pathways are induced by PDIA1 in the ER $\alpha$-positive vs. the ER $\alpha$-negative breast cancers allowing the hypothesis that these two types of breast cancer can be treated differentially by drugs targeting cell cycle progression (ER $\alpha$-positive breast cancers) or evasion of immunosurveillance (ER $\alpha$-negative breast cancers).

\section{Acknowledgements}

We thank Dr T. Geladopoulos for reading the manuscript and providing constructive suggestions.

\section{Funding}

No funding was received. 


\section{Availability of data and materials}

RNA-seq data are available and can be accessed at the link: https://www.ncbi.nlm.nih.gov/geo/query/acc. cgi?acc=GSE188914.

\section{Authors' contributions}

Conceptualization of the study concept was carried out by MKD, CD and RA. Data curation was conducted by EYB, CD, and RA. Formal analysis and confirmation of the data were conducted by EYB and RA. Funding acquisition was achieved by $\mathrm{CD}$ and $\mathrm{RA}$. Investigations, including bioinformatics database search, data collection and data analysis, were the responsibility of EYB and RA. Research methodology was the responsibility of EYB, CD, and RA. Project administration was conducted by $\mathrm{CD}$ and RA. Resources were the responsibility of CD and RA. Supervision was undertaken by MF, MKD, and CD. Visualization was conducted by EYB, RA, MKD and CD. Writing of the original draft was carried out by EYB, MKD, $\mathrm{CD}$, and RA. Writing, review and editing were carried out by EYB, MF, MKD, CD, and RA. All authors read and agreed to the published version of the manuscript.

\section{Ethics approval and consent to participate}

Not applicable.

\section{Patient consent for publication}

Not applicable.

\section{Competing interests}

The authors declare no competing interests.

\section{References}

1. Riemer J, Appenzeller-Herzog C, Johansson L, Bodenmiller B, Hartmann-Petersen R and Ellgaard L: A luminal flavoprotein in endoplasmic reticulum-associated degradation. Proc Natl Acad Sci USA 106: 14831-14836, 2009.

2. Moretti AI and Laurindo FR: Protein disulfide isomerases: Redox connections in and out of the endoplasmic reticulum. Arch Biochem Biophys 617: 106-119, 2017.

3. Hudson DA, Gannon SA and Thorpe C: Oxidative protein folding: From thiol-disulfide exchange reactions to the redox poise of the endoplasmic reticulum. Free Radic Biol Med 80 171-182, 2015.

4. Alhammad R, Khunchai S, Tongmuang N, Limjindaporn T, Yenchitsomanus PT, Mutti L, Krstic-Demonacos M and Demonacos C: Protein disulfide isomerase A1 regulates breast cancer cell immunorecognition in a manner dependent on redox state. Oncol Rep 44: 2406-2418, 2020.

5. Grek C and Townsend DM: Protein disulfide isomerase superfamily in disease and the regulation of apoptosis. Endoplasmic Reticulum Stress Dis 1: 4-17, 2014.

6. Jang I, Pottekat A, Poothong J, Yong J, Lagunas-Acosta J, Charbono A, Chen Z, Scheuner DL, Liu M, Itkin-Ansari P, et al: PDIA1/P4HB is required for efficient proinsulin maturation and $\beta$ cell health in response to diet induced obesity. ELife 8: e44528, 2019.

7. Kukita K, Tamura Y, Tanaka T, Kajiwara T, Kutomi G, Saito K, Okuya K, Takaya A, Kanaseki T, Tsukahara T, et al: Cancer-associated oxidase ERO1- $\alpha$ regulates the expression of MHC class I molecule via oxidative folding. J Immunol 194: 4988-4996, 2015.
8. Park B, Lee S, Kim E, Cho K, Riddell SR, Cho S and Ahn K: Redox regulation facilitates optimal peptide selection by MHC class I during antigen processing. Cell 127: 369-382, 2006.

9. Tanaka T, Kutomi G, Kajiwara T, Kukita K, Kochin V, Kanaseki T, Tsukahara T, Hirohashi Y, Torigoe T, Okamoto Y, et al: Cancer-associated oxidoreductase ERO1- $\alpha$ promotes immune escape through up-regulation of PD-L1 in human breast cancer. Oncotarget 8: 24706-24718, 2017.

10. Lee $\mathrm{E}$ and Lee $\mathrm{DH}$ : Emerging roles of protein disulfide isomerase in cancer. BMB Rep 50: 401-410, 2017.

11. Xu S, Sankar S and Neamati N: Protein disulfide isomerase: A promising target for cancer therapy. Drug Discov Today 19: 222-240, 2014.

12. Wise R, Duhachek-Muggy S, Qi Y, Zolkiewski M and Zolkiewska A: Protein disulfide isomerases in the endoplasmic reticulum promote anchorage-independent growth of breast cancer cells. Breast Cancer Res Treat 157: 241-252, 2016.

13. Thongwatchara P, Promwikorn W, Srisomsap C, Chokchaichamnankit D, Boonyaphiphat $\mathrm{P}$ and Thongsuksai P: Differential protein expression in primary breast cancer and matched axillary node metastasis. Oncol Rep 26: 185-191, 2011.

14. Zou H, Wen C, Peng Z, Shao YY, Hu L, Li S, Li C and Zhou HH: $\mathrm{P} 4 \mathrm{HB}$ and PDIA3 are associated with tumor progression and therapeutic outcome of diffuse gliomas. Oncol Rep 39: 501-510, 2018.

15. Ma X, Wang J, Zhuang J, Ma X, Zheng N, Song Y and Xia W: P4HB modulates epithelial-mesenchymal transition and the $\beta$-catenin/snail pathway influencing chemoresistance in liver cancer cells. Oncol Lett 20: 257-265, 2020.

16. Xia W, Zhuang J, Wang G, Ni J, Wang J and Ye Y: P4HB promotes HCC tumorigenesis through downregulation of GRP78 and subsequent upregulation of epithelial-to-mesenchymal transition. Oncotarget 8: 8512-8521, 2017.

17. Zhang Y, Li T, Zhang L, Shangguan F, Shi G, Wu X, Cui Y, Wang X, Wang X, Liu Y, et al: Targeting the functional interplay between endoplasmic reticulum oxidoreductin-1 $\alpha$ and protein disulfide isomerase suppresses the progression of cervical cancer. EBioMedicine 41: 408-419, 2019.

18. Zhang J, Wu Y, Lin YH, Guo S, Ning PF, Zheng ZC, Wang Y and Zhao Y: Prognostic value of hypoxia-inducible factor-1 alpha and prolyl 4-hydroxylase beta polypeptide overexpression in gastric cancer. World J Gastroenterol 24: 2381-2391, 2018.

19. Yousef EM, Tahir MR, St-Pierre Y and Gaboury LA: MMP-9 expression varies according to molecular subtypes of breast cancer. BMC Cancer 14: 609, 2014.

20. Bartels AK, Göttert S, Desel C, Schäfer M, Krossa S, Scheidig AJ, Grötzinger J and Lorenzen I: KDEL receptor 1 contributes to cell surface association of protein disulfide isomerases. Cell Physiol Biochem 52: 850-868, 2019.

21. Khan HA and Mutus B: Protein disulfide isomerase a multifunctional protein with multiple physiological roles. Front Chem 2: 70, 2014.

22. Wiersma VR, Michalak M, Abdullah TM, Bremer E and Eggleton P: Mechanisms of translocation of ER chaperones to the cell surface and immunomodulatory roles in cancer and autoimmunity. Front Oncol 5: 7, 2015.

23. Brigelius-Flohé R and Flohé L: Basic principles and emerging concepts in the redox control of transcription factors. Antioxid Redox Signal 15: 2335-2381, 2011.

24. Zhang K: Endoplasmic reticulum stress response and transcriptional reprogramming. Front Genet 5: 460, 2015.

25. Fu X, Wang P and Zhu BT: Protein disulfide isomerase is a multifunctional regulator of estrogenic status in target cells. J Steroid Biochem Mol Biol 112: 127-137, 2008.

26. Schultz-Norton JR, McDonald WH, Yates JR and Nardulli AM: Protein disulfide isomerase serves as a molecular chaperone to maintain estrogen receptor $\alpha$ structure and function. Mol Endocrinol 20: 1982-1995, 2006.

27. Higuchi T, Watanabe $Y$ and Waga I: Protein disulfide isomerase suppresses the transcriptional activity of NF- $\kappa \mathrm{B}$. Biochem Biophys Res Commun 318: 46-52, 2004.

28. Xiao Y, Li C, Gu M, Wang H, Chen W, Luo G, Yang G, Zhang Z, Zhang Y, Xian G, et al: Protein disulfide isomerase silence inhibits inflammatory functions of macrophages by suppressing reactive oxygen species and $\mathrm{NF}-\kappa \mathrm{B}$ pathway. Inflammation 41 : 614-625, 2018. 
29. Kranz P, Neumann F, Wolf A, Classen F, Pompsch M Ocklenburg T, Baumann J, Janke K, Baumann M, Goepelt K, et al: PDI is an essential redox-sensitive activator of PERK during the unfolded protein response (UPR). Cell Death Dis 8: e2986-e2986, 2017.

30. Zhou Y, Yang J, Zhang Q, Xu Q, Lu L, Wang J and Xia W: P4HB knockdown induces human HT29 colon cancer cell apoptosis through the generation of reactive oxygen species and inactivation of STAT3 signaling. Mol Med Rep 19: 231-237, 2019.

31. Frasor J, Weaver A, Pradhan M, Dai Y, Miller LD, Lin CY and Stanculescu A: Positive cross-talk between estrogen receptor and NF-kappaB in breast cancer. Cancer Res 69: 8918-8925, 2009.

32. Lee LC, Weng YT, Wu YR, Soong BW, Tseng YC, Chen CM and Lee-Chen GJ: Downregulation of proteins involved in the endoplasmic reticulum stress response and Nrf2-ARE signaling in lymphoblastoid cells of spinocerebellar ataxia type 17 . J Neural Transm (Vienna) 121: 601-610, 2014.

33. Campos JLO, Doratioto TR, Videira NB, Filho HVR, Batista FA, Fattori J, de C Indolfo N, Nakahira M, Bajgelman MC, Cvoro A, et al: Protein disulfide isomerase modulates the activation of thyroid hormone receptors. Front Endocrinol (Lausanne) 9: 784, 2019.

34. Hashimoto $\mathrm{S}$ and Imaoka S: Protein-disulfide isomerase regulates the thyroid hormone receptor-mediated gene expression via redox factor-1 through thiol reduction-oxidation. J Biol Chem 288: 1706-1716, 2013.

35. Kimura T, Horibe T, Sakamoto C, Shitara Y, Fujiwara F, Komiya T, Yamamoto A, Hayano T, Takahashi N and Kikuch M: Evidence for mitochondrial localization of P5, a member of the protein disulphide isomerase family. J Biochem 144: 187-196, 2008.

36. Fan Y and Simmen T: Mechanistic connections between endoplasmic reticulum (ER) redox control and mitochondrial metabolism. Cells 8: 1071, 2019.

37. Kaufman RJ and Malhotra JD: Calcium trafficking integrates endoplasmic reticulum function with mitochondrial bioenergetics. Biochim Biophys Acta 1843: 2233-2239, 2014.

38. Luo B and Lee AS: The critical roles of endoplasmic reticulum chaperones and unfolded protein response in tumorigenesis and anticancer therapies. Oncogene 32: 805-818, 2013.

39. Spencer NG, Schilling T, Miralles F and Eder C: Mechanisms underlying interferon- $\gamma$-induced priming of microglial reactive oxygen species production. PLoS One 11: e0162497-e0162497, 2016.

40. Shin HJ, Kwon HK, Lee JH, Anwar MA and Choi S: Etoposide induced cytotoxicity mediated by ROS and ERK in human kidney proximal tubule cells. Sci Rep 6: 34064, 2016.

41. Kuhn RM, Haussler D and Kent WJ: The UCSC genome browser and associated tools. Brief Bioinform 14: 144-161, 2012.

42. Dobin A, Davis CA, Schlesinger F, Drenkow J, Zaleski C, Jha S Batut P, Chaisson M and Gingeras TR: STAR: Ultrafast universal RNA-seq aligner. Bioinformatics 29: 15-21, 2013.

43. Karolchik D, Baertsch R, Diekhans M, Furey TS, Hinrichs A, Lu YT, Roskin KM, Schwartz M, Sugnet CW, Thomas DJ, et al: The UCSC genome browser database. Nucleic Acids Res 31: $51-54,2003$.

44. Okonechnikov K, Conesa A and García-Alcalde F: Qualimap 2: Advanced multi-sample quality control for high-throughput sequencing data. Bioinformatics 32: 292-294, 2016.

45. Li H, Handsaker B, Wysoker A, Fennell T, Ruan J, Homer N, Marth G, Abecasis G and Durbin R; 1000 Genome Project Data Processing Subgroup: The sequence alignment/map format and SAMtools. Bioinformatics 25: 2078-2079, 2009.

46. Robinson JT, Thorvaldsdóttir H, Winckler W, Guttman M, Lander ES, Getz G and Mesirov JP: Integrative genomics viewer. Nat Biotechnol 29: 24-26, 2011.

47. Liao Y, Smyth GK and Shi W: The R package Rsubread is easier, faster, cheaper and better for alignment and quantification of RNA sequencing reads. Nucleic Acids Res 47: e47, 2019.

48. Stel VS, Dekker FW, Tripepi G, Zoccali C and Jager KJ: Survival analysis I: The kaplan-meier method. Nephron Clin Pract 119 c83-c88, 2011.

49. Li Q, Birkbak NJ, Gyorffy B, Szallasi Z and Eklund AC: Jetset: Selecting the optimal microarray probe set to represent a gene. BMC Bioinformatics 12: 474, 2011.

50. Stelzer G, Rosen N, Plaschkes I, Zimmerman S, Twik M, Fishilevich S, Stein TI, Nudel R, Lieder I, Mazor Y, et al: The GeneCards suite: From gene data mining to disease genome sequence analyses. Curr Protoc Bioinformatics 54: 1.30.31-31.30.33, 2016 .
51. Zhou Y, Zhou B, Pache L, Chang M, Khodabakhshi AH, Tanaseichuk O, Benner C and Chanda SK: Metascape provides a biologist-oriented resource for the analysis of systems-level datasets. Nat Commun 10: 1523, 2019.

52. Amelio I, Gostev M, Knight RA, Willis AE, Melino G and Antonov AV: DRUGSURV: A resource for repositioning of approved and experimental drugs in oncology based on patient survival information. Cell Death Dis 5: e1051, 2014.

53. Kawasaki $\mathrm{T}$ and Kawai $\mathrm{T}$ : Toll-like receptor signaling pathways. Front Immunol 5: 461, 2014.

54. Ebersole JL, Novak MJ, Orraca L, Martinez-Gonzalez J, Kirakodu S, Chen KC, Stromberg A and Gonzalez OA: Hypoxia-inducible transcription factors, HIF1A and HIF2A, increase in aging mucosal tissues. Immunology 154: 452-464, 2018.

55. Kiefel H, Bondong S, Hazin J, Ridinger J, Schirmer U, Riedle S and Altevogt P: L1CAM: A major driver for tumor cell invasion and motility. Cell Adh Migr 6: 374-384, 2012

56. Blom M, Reis K, Heldin J, Kreuger J and Aspenström P: The atypical Rho GTPase RhoD is a regulator of actin cytoskeleton dynamics and directed cell migration. Exp Cell Res 352: 255-264, 2017.

57. Filippou PS, Karagiannis GS and Constantinidou A: Midkine (MDK) growth factor: A key player in cancer progression and a promising therapeutic target. Oncogene 39: 2040-2054, 2020.

58. Wang ZC, Gao Q, Shi JY, Guo WJ, Yang LX, Liu XY, Liu LZ, Ma LJ, Duan M, Zhao YJ, et al: Protein tyrosine phosphatase receptor $\mathrm{S}$ acts as a metastatic suppressor in hepatocellular carcinoma by control of epithermal growth factor receptor-induced epithelial-mesenchymal transition. Hepatology 62: 1201-1214, 2015.

59. Tseng CW, Kuo WH, Chan SH, Chan HL, Chang KJ and Wang LH: Transketolase regulates the metabolic switch to control breast cancer cell metastasis via the $\alpha$-ketoglutarate signaling pathway. Cancer Res 78: 2799-2812, 2018

60. Yi JW, Park JY, Sung JY, Kwak SH, Yu J, Chang JH, Kim JH, Ha SY, Paik EK, Lee WS, et al: Genomic evidence of reactive oxygen species elevation in papillary thyroid carcinoma with Hashimoto thyroiditis. Endocr J 62: 857-877, 2015.

61. Wang SH, Chen YL, Hsiao JR, Tsai FY, Jiang SS, Lee AYL, Tsai HJ and Chen YW: Insulin-like growth factor binding protein 3 promotes radiosensitivity of oral squamous cell carcinoma cells via positive feedback on NF- $\kappa B / I L-6 / R O S$ signaling. J Exp Clin Cancer Res 40: 95, 2021

62. Hofer-Warbinek R, Schmid JA, Stehlik C, Binder BR, Lipp J and de Martin R: Activation of NF-kappa B by XIAP, the X chromosome-linked inhibitor of apoptosis, in endothelial cells involves TAK1. J Biol Chem 275: 22064-22068, 2000.

63. Darshi M, Mendiola VL, Mackey MR, Murphy AN, Koller A, Perkins GA, Ellisman MH and Taylor SS: ChChd3, an inner mitochondrial membrane protein, is essential for maintaining crista integrity and mitochondrial function. J Biol Chem 286: 2918-2932, 2011

64. Schneble N, Müller J, Kliche S, Bauer R, Wetzker R, Böhmer FD Wang ZQ and Müller JP: The protein-tyrosine phosphatase DEP-1 promotes migration and phagocytic activity of microglial cells in part through negative regulation of fyn tyrosine kinase. Glia 65: 416-428, 2017.

65. Tabach Y, Milyavsky M, Shats I, Brosh R, Zuk O, Yitzhaky A, Mantovani R, Domany E, Rotter V and Pilpel Y: The promoters of human cell cycle genes integrate signals from two tumor suppressive pathways during cellular transformation. Mol Syst Biol 1: 2005.0022, 2005.

66. Fu J, Bian M, Jiang Q and Zhang C: Roles of Aurora kinases in mitosis and tumorigenesis. Mol Cancer Res 5: 1-10, 2007.

67. Gao T, Han Y, Yu L, Ao S, Li Z and Ji J: CCNA2 is a prognostic biomarker for ER+ breast cancer and tamoxifen resistance. PLoS One 9: e91771, 2014

68. Cangi MG, Cukor B, Soung P, Signoretti S, Moreira G Jr, Ranashinge M, Cady B, Pagano M and Loda M: Role of the Cdc25A phosphatase in human breast cancer. J Clin Invest 106: 753-761, 2000.

69. Rapley J, Nicolàs M, Groen A, Regué L, Bertran MT, Caelles C, Avruch J and Roig J: The NIMA-family kinase Nek6 phosphorylates the kinesin Eg5 at a novel site necessary for mitotic spindle formation. J Cell Sci 121: 3912-3921, 2008.

70. Nami B and Wang Z: Genetics and expression profile of the tubulin gene superfamily in breast cancer subtypes and its relation to taxane resistance. Cancers (Basel) 10: 274, 2018. 
71. Lin T, Qiu Y, Peng W and Peng L: Heat shock protein 90 family isoforms as prognostic biomarkers and their correlations with immune infiltration in breast cancer. Biomed Res Int 2020: 2148253,2020

72. Glowacka WK, Alberts P, Ouchida R, Wang JY and Rotin D: LAPTM5 protein is a positive regulator of proinflammatory signaling pathways in macrophages. J Biol Chem 287: 27691-27702, 2012.

73. Sharma P, Barlow WE, Godwin AK, Parkes EE, Knight LA, Walker SM, Kennedy RD, Harkin DP, Logan GE, Steele CJ, et al: Validation of the DNA damage immune response signature in patients with triple-negative breast cancer from the SWOG 9313c trial. J Clin Oncol 37: 3484-3492, 2019.
74. Leung KL, Verma D, Azam YJ and Bakker E: The use of multi-omics data and approaches in breast cancer immunotherapy: A review. Future Oncol 16: 2101-2119, 2020.

75. Sabbatino F, Liguori L, Polcaro G, Salvato I, Caramori G, Salzano FA, Casolaro V, Stellato C, Col JD and Pepe S: Role of human leukocyte antigen system as a predictive biomarker for checkpoint-based immunotherapy in cancer patients. Int J Mol Sci 21: 7295, 2020 .

(i) (9) This work is licensed under a Creative Commons EY NO ND Attribution-NonCommercial-NoDerivatives 4.0 International (CC BY-NC-ND 4.0) License. 